\title{
Continuous Feeding of Low-Dose APIs via Periodic Micro Dosing
}

\author{
M. O. Besenhard ${ }^{1}$, S. Karkala ${ }^{2}$, E. Faulhammer ${ }^{1}$, S. Fathollahi ${ }^{1}$, R. Ramachandran ${ }^{2}$, J. G. Khinast ${ }^{1,3^{*}}$ \\ 1: Research Center Pharmaceutical Engineering (RCPE) GmbH, 8010 Graz, Austria \\ 2: Rutgers University, Department of Chemical \& Biochemical Engineering, New Jersey, USA \\ 3: Graz University of Technology, Institute for Process and Particle Engineering, 8010 Graz, Austria
}

* Corresponding author. Tel.: +43 (316) 873 - 30400; Fax: +43 (0) 316 /873-30402; E-mail address: khinast@tugraz.at

\begin{abstract}
:
Precise and effective feeding of small powder quantities remains a challenge in many fields, including pharmaceutical development and production. This paper demonstrates that a simple feeding principle can be applied to accomplish stable micro feeding $(<100 \mathrm{mg} / \mathrm{s}$ ) and describes a gravimetric powder feeding system with a vibratory sieve mounted on a chute. Feeding was induced via vertical vibrations that can be adjusted within a broad range of frequencies and amplitudes. The feeding system was studied using different frequencies, amplitudes, sieves and powder properties. Feeding was characterized by means of a dynamic scale and high-speed camera recordings. The feeding system provided effective powder feeding even in a range of $1-2 \mathrm{mg} / \mathrm{s}$. It was shown that powder properties require special attention when the vibratory sieve-chute system operates at higher feed rates (or feeding times $>30 \mathrm{~min}$ ), i.e., feeding at a higher throughput.

A combination of discrete element method (DEM) simulations and compartment population balance model (PBM) was used to incorporate the proposed micro feed system into a continuous powder mixer (Gerike GCM250; Gerike Holding LTD., Regensdorf, Switzerland). It illustrates how oscillating feeding rates (the latter is a characteristic of the studied micro feeding system) affect the content uniformity of low dose blends, i.e., powder mixtures with a relatively low fraction of active pharmaceutical ingredient.
\end{abstract}

\section{Keywords:}

powder feeding; micro feeding; continuous blending; vibratory sieve; feed rate robustness; DEM; compartment model

(C) 2016. This manuscript version is made available under the Elsevier user license http://www.elsevier.com/open-access/userlicense/1.0/ 


\section{Introduction}

Handling small quantities of powder is a common practice in pharmaceutical development, which is currently gaining importance in the pharmaceutical production due to new operation procedures and manufacturing strategies, including accurate and robust strategies for micro feeding $(<100 \mathrm{mg} / \mathrm{s})$ of powders. Another aspect is the increasing fraction of high-potency active pharmaceutical ingredients (HPAPI) in the development pipelines with only a few mg of active substance in the formulation [1]. Direct dosing of API into capsules [2][3], generating low-dose blends for HPAPIs [4][5] and creating seeding strategies for crystallization processes [6][7] are just a few instances in which robust powder feeding at feed rates of several milligrams per second is required. In addition, in several flow chemistry applications, direct powder feeding into a fluid stream would eliminate sampling issues associated with feeding from a reservoir suspension [8]-[10]. Yet powder feeders that allow sufficiently low feed rates are unavailable, especially with feeding rates $<5 \mathrm{mg} / \mathrm{s}$. With regard to such small powder quantities, the influence of powder/wall interactions cannot be neglected due to a high surface-to-volume ratios, e.g., in small cavities, channels or tubing. Since gravitational forces are comparatively small, inter-particle forces become important. Overall, feeding strategies for micro feeders thus differ from those for common powder feeders [11]-[13].

There is no strict distinction between powder dosing (i.e., dispensing discrete powder entities) and feeding (i.e., permanent outflow of powder). By increasing the dosing frequency (i.e., number of powder releases per time) and decreasing the amount of dispended powder, multiple powder dosing events may be considered feeding. Hence, microdosing systems can serve as micro feeders based on the feeding requirements. As discussed in [14], dosing of small powder entities is relevant in the field of granular 3D printing that became state-of-the-art in the recent years [15][16]. Several recent developments and micro dosing/feeding prototypes address free-forming method, such as 3D printing. Table 1 provides an overview of micro feeders and their feeding principles. Many of them involve small capillaries that obstruct the powder flow via arching, plugging and blocking [17] in the absence of agitation. Vibration-assisted powder feeding through a narrow orifice is a well-established concept [18]. However, due to strict regulatory requirements with regard to the dose and content uniformity, pharmaceutical processes require highly accurate dispensing and feeding.

This paper describes micro feeding via a gravimetric powder feeding system with a vibratory sieve mounted on a chute. While our earlier work [14] focused on micro dosing of capsules via a vibratory sieve-chute system, the current one addresses the micro feeding properties of such a system. The feeder was tested in terms of feasible feed rates, feed robustness and reproducibility. A compartment model that utilizes Discrete Element Method (DEM) simulation results was used to investigate how a micro feeder can be incorporated into a continuous powder mixer in order to generate a low-dose blend. The model predicts the content uniformity achieved during ideal micro feeding and in the presence of feed rate fluctuations, which are typical during vibration-assisted powder feeding. 
Table 1: Various micro feeders and their feeding principles

\begin{tabular}{|c|c|c|c|c|}
\hline Feeding Rates & 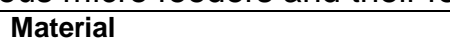 & Feeding Principle & Comments & Source \\
\hline $1-10 \mathrm{mg} / \mathrm{s}$ & $\begin{array}{l}\text { Lactose powders; } \\
X_{50}: 66-206 \mu \mathrm{m}\end{array}$ & $\begin{array}{l}\text { Vibrating capillary; } \\
\text { Capillary orifices } \sim 8 \mathrm{~mm} \\
\text { Frequencies } 1000-1500 \mathrm{~Hz}\end{array}$ & & [19] \\
\hline $0.5-11 \mathrm{mg} / \mathrm{s}$ & $\begin{array}{l}\text { Cu }(10-100 \mu m), \mathrm{Zn}(20- \\
150 \mu m), \text { Fe powders }(50- \\
200 \mu m)\end{array}$ & $\begin{array}{l}\text { Vibrating capillary; } \\
\text { Capillary orifices } \sim 150-360 \mu \mathrm{m} \\
\text { Ultrasonic vibration, } 46.45 \mathrm{kHz}\end{array}$ & $\begin{array}{l}\text { Powders were sieved } \\
\text { depending on the capillary } \\
\text { used }\end{array}$ & {$[20]$} \\
\hline$\sim 0.8-7.5 \mathrm{mg} / \mathrm{s}$ & $\begin{array}{l}\text { Alumina powders; } \\
X_{50}: 6-20 \mu \mathrm{m}\end{array}$ & $\begin{array}{l}\text { Vibrating capillary; } \\
\text { Capillary orifices } \sim 0.4-1.6 \mathrm{~mm} ; \\
\text { Frequencies }<760 \mathrm{~Hz}\end{array}$ & & [21] \\
\hline $\begin{array}{l}\sim 0.15- \\
-10 \mathrm{mg} / \mathrm{s}\end{array}$ & $\begin{array}{l}\text { Metal }(<22 \mu \mathrm{m}) \\
\text { ceramic }(0.1 \mu \mathrm{m}, 0.18 \mu \mathrm{m}, 12 \mu \mathrm{m},) \text {, } \\
\text { and glass powders }(42 \mu \mathrm{m})\end{array}$ & $\begin{array}{l}\text { Vibrating capillary; } \\
\text { Capillary/nozzle orifices } 0.21-1.35 \mathrm{~mm} \text {; } \\
\text { Ultrasonic vibration }\end{array}$ & $\begin{array}{l}\text { Spherical piezoelectric } \\
\text { ceramic ring for vibrations, } \\
\text { oscillation through a water } \\
\text { tank }\end{array}$ & [17][22] \\
\hline $24-85 \mathrm{mg} / \mathrm{s}$ & $\begin{array}{l}\text { Microcrystalline cellulose powders; } \\
X_{50}: 50-170 \mu \mathrm{m}\end{array}$ & $\begin{array}{l}\text { Vibration shear tube, powder discharge } \\
\text { through a narrow gap between vibrating } \\
\text { tube edge and flat bottom surface; } \\
\text { Tube orifices }=8 \mathrm{~mm} ; \\
\text { Gap distance }=0.8 \mathrm{~mm} ; \\
\text { Frequency } 280 \mathrm{~Hz}\end{array}$ & $\begin{array}{l}\text { Effect of different aspect } \\
\text { ratios/particle shapes was } \\
\text { investigated. }\end{array}$ & [23] \\
\hline $7-24 \mathrm{mg} / \mathrm{s}$ & $\begin{array}{l}\text { Lactose }(\text { InhaLac } \AA 70) ; \\
X_{50}=200 \mu \mathrm{m}\end{array}$ & $\begin{array}{l}\text { High frequency vibration to control flow out } \\
\text { of a narrow hopper; } \\
\text { Nozzle orifice }=0.9-1.2 \mathrm{~mm} ; \\
\text { Frequency } \sim 4 \mathrm{kHz}\end{array}$ & $\begin{array}{l}\text { Hopper vibrated for } 0.5 \mathrm{~s}, \\
\text { followed by a } 5-10 \mathrm{~s} \\
\text { pause. Dose from each } \\
\text { vibration period was } \\
\text { averaged. }\end{array}$ & {$[18]$} \\
\hline $8-862 \mathrm{mg} / \mathrm{s}$ & $\begin{array}{l}\text { Lactose }(1-5 \mu m, 5-10 \mu m) \\
\text { Cromolyn sodium }(1-5 \mu m), \\
\text { Characoal }(75-120 \mu m, \ldots, 300- \\
500 \mu m), \text { sodium chloride }(1- \\
10 \mu m, \ldots, 180-300 \mu m)\end{array}$ & $\begin{array}{l}\text { Vibrating spatula; } \\
\text { Vibration with constant frequency }\end{array}$ & $\begin{array}{l}\text { Highly variable feeding } \\
\text { rates. }\end{array}$ & {$[24]$} \\
\hline$\sim 15-180 \mathrm{mg} / \mathrm{s}$ & Zinc oxide powder $(<1 \mu \mathrm{m})$ & $\begin{array}{l}\text { Screw-brush feeding system for gas- } \\
\text { particle flow }\end{array}$ & $\begin{array}{l}\text { Feeding concept to avoid } \\
\text { aggregation. }\end{array}$ & [25] \\
\hline $\begin{array}{l}\text { Gravity } \\
\text { assisted } \sim 15- \\
360 \mathrm{mg} / \mathrm{s} \\
\text { Vibration } \\
\text { assisted } \sim 3- \\
14 \mathrm{mg} / \mathrm{s} \text { nozzle } \\
\text { orifices } \leq 2 \mathrm{~mm} \\
(\text { nozzle orifices = } \\
0.5 \mathrm{~mm} \text { ) }\end{array}$ & $\begin{array}{l}\text { High-quality soda-lime glass } \\
\text { beads; } \\
38-125 \mu \mathrm{m}\end{array}$ & $\begin{array}{l}\text { Deposition through miniature hopper- } \\
\text { nozzles; } \\
\text { Gravity (nozzle orifices } \sim 0.75-2 \mathrm{~mm} \text {, } \\
\text { pressure, and vibration assisted (nozzle } \\
\text { orifices } \leq 2 \mathrm{~mm} \text {, frequencies } 8-15 \mathrm{kHz} \text {, } \\
\text { particle sizes }<60 \mu \mathrm{m} \text { ) }\end{array}$ & $\begin{array}{l}\text { Gravity assisted feeding } \\
\text { rates were calculated } \\
\text { based on equation } 2 \text { in the } \\
\text { paper. Pressure assisted } \\
\text { flow yielded unpredictable } \\
\text { feeding rates }\end{array}$ & {$[26]$} \\
\hline
\end{tabular}




\section{Materials and Methods}

\subsection{Materials}

In this study, two powders (hereinafter referred to as powder I and powder II) of inhalation-grade $\alpha$-lactose monohydrate with different particle sizes and supplied by different manufacturers (DFE Pharma, Goch, Germany and Meggle, Wasserburg am Inn, Germany), as received. The same powders were used in our previous work [14], which contains a detailed description of the characterization procedures. Since new powder samples, i.e., new batches, were provided for this study, powder properties were characterized again (see Table 2, the results are in good agreement with [14]). Properties not mentioned in [14] were determined as described below.

Particle Size Characterization

QICPIC (OASIS/L dry dispersing system Sympatec, Clausthal-Zellerfeld, Germany) was employed to measure the size (volumetric mean diameter, VMD and median particle size) and shape of millions of particles in each sample via dynamic image analysis. Two-dimensional images of a particle were interpreted in terms of the minimum and maximum Feret diameters $\left(\mathrm{F}_{\text {min }}, \mathrm{F}_{\text {max }}\right)$. Aspect ratio $(A R)$ is the ratio between $\mathrm{F}_{\min }$ and $\mathrm{F}_{\text {max }}$ that describes the shape of particles. Its value can be between 0 and 1 . It reflects the deviation of its shape from a sphere. The higher the value is, the more spherical the shape is. Particle size distributions (PSDs) of powders I and II are shown in the Supplementary Information (SI 1: Particle Size Distribution of the Powders).

\section{Density and Flow Characteristics}

The bulk (BD) and tapped densities (TD) were analyzed (Pharmatest PT-TD200; Pharma Test, Hainburg, Germany) via a standardized method described in the United States Pharmacopeia (USP 2011, 616). The powder was filled into a cylinder and the level was recorded. The tapped density was attained after mechanically tapping the powder sample and recording the level again. The two levels were used to estimate the flow index (Carr's compressibility index). The Angle of Repose (AoR) was determined using a glass funnel described in the pharmacopoeia (USP 2007, 1174).

\subsection{Vibratory Sieve Chute System}

The study was performed using a feeder with a vibratory sieve (oscillating vertically) mounted on a chute $(2.5 \mathrm{~cm})$ and directing the powder into an orifice, i.e., the outlet as shown in Fig. 1. A feeding unit of the MG2 Microdose ${ }^{\circledR}$ (MG2; Bologna, Italy) stand-alone unit, i.e., a capsule filler, was used, with the chute tilted at a fixed angle of $5^{\circ}$ and the sieve

fixed on top. The sieve had six holes, all with a diameter of $d_{\text {hole }}=0.7 \mathrm{~mm}$. Feeding was studied with a varying number of sieve holes (min. $1-\max .5)$.

The system allowed for vibrations within a broad range of amplitudes and frequencies that were set independently. The amplitude setting refers to the driving force of the linear voice coil motor moving the sieve-chute system vertically. In this work, the driving force was quantified by the entity $E$. A detailed description of the vibratory sieve chute system, including an analysis of the vertical accelerations profiles, is presented in [14]. An amplitude setting of $50 E$ yielded the 
maximum acceleration values of $a \approx 3.5 \mathrm{~g}\left(1 \mathrm{~g}=9.8 \mathrm{~m} / \mathrm{s}^{2}\right)$ during an oscillation, while $80 E$ resulted in $\approx 6 \mathrm{~g}$. It was shown, that the system oscillates rather pulsating than smoothly, i.e., no sinusoidal oscillations occur. However, acceleration profiles $a(t)$ of single oscillations are consistent, which enables robust feeding.

Since powder exits the sieve once per oscillation in the vibratory settings (see SI 2 and videos provided in Supplemental Information), feeding rates can fluctuate with a periodicity of the vibration frequency, even if the chute is smoothing these fluctuations.

In [14], the filling rates (i.e., feed rates of the Microdose ${ }^{\circledR}$ feeding unit) into capsules of powder I and powder II were analyzed using frequencies between $10-100 \mathrm{~Hz}$ and amplitudes between $20-100 \mathrm{E}$. Robust feeding, i.e., with low standard deviations of the filling rate, was achieved for specific ranges. Here, we studied micro-feeding using two settings that facilitated robust feeding during capsule filling ([14], Figure 7 \& 9). The settings for low and high feeding rates are listed in Table 2 together with the powder properties.

Table 2: Powder properties of the three-inhalation carriers and vibrating settings

\begin{tabular}{|c|c|c|c|c|c|c|c|c|c|c|c|}
\hline $\begin{array}{c}\text { Name } \\
\text { (Manufacturing } \\
\text { characteristics/Batc } \\
\text { h no.) }\end{array}$ & $\begin{array}{l}\text { Low } \\
\text { setting }\end{array}$ & $\begin{array}{l}\text { High } \\
\text { setting }\end{array}$ & AoR & AR & $\begin{array}{c}\mathrm{x}_{10} \\
{[\mu \mathrm{m}]}\end{array}$ & $\begin{array}{c}x_{50} \\
{[\mu \mathrm{m}]}\end{array}$ & $\begin{array}{c}\mathrm{X}_{90} \\
{[\mu \mathrm{m}]}\end{array}$ & $\begin{array}{c}\text { Span } \\
\left(x_{90}-x_{10}\right) / x_{50}\end{array}$ & $\begin{array}{l}\text { Bulk } \\
\text { density } \\
{\left[\mathrm{g} / \mathrm{cm}^{3}\right]}\end{array}$ & $\begin{array}{l}\text { Tapped } \\
\text { density } \\
{\left[\mathrm{g} / \mathrm{cm}^{3}\right]}\end{array}$ & $\begin{array}{c}\text { Carr } \\
\text { Index } \\
{[-]}\end{array}$ \\
\hline $\begin{array}{l}\text { InhaLac } 230 \\
\text { (Lot: L158421) } \\
\text { Meggle, } \\
\text { Wasserburg am Inn, } \\
\text { Germany } \\
\text { Powder I }\end{array}$ & $\begin{array}{c}15 \mathrm{~Hz} \\
75 \mathrm{E}\end{array}$ & $\begin{array}{c}90 \mathrm{~Hz} \\
90 \mathrm{E}\end{array}$ & 33.02 & 0.67 & 79.2 & 114.7 & 149.2 & 0.61 & 0.72 & 0.88 & 19.2 \\
\hline $\begin{array}{l}\text { Respitose SV003 } \\
\text { (Lot: 1068000) DFE } \\
\text { Pharma, Goch, } \\
\text { Germany } \\
\text { Powder II }\end{array}$ & $\begin{array}{c}15 \mathrm{~Hz} \\
75 \mathrm{E}\end{array}$ & $\begin{array}{c}80 \mathrm{~Hz} \\
80 \mathrm{E}\end{array}$ & 35.87 & 0.69 & 46.1 & 71.0 & 100.0 & 0.76 & 0.67 & 0.85 & 20.8 \\
\hline
\end{tabular}

\subsection{Feeding Analysis}

The feeding characteristics of the vibratory-sieve chute system were studied using the setup shown in Figure 1 . The outlet of the feeding system was placed above a lab scale (0 - $220 \mathrm{~g}$ Sartorius AW-224; Goettingen, Germany) with a mounted draft shield. During feeding into a weighing dish, weight was recorded once per second via the scale's serial port and a LabVIEW (National Instruments Corporation, Austin, USA) program.

In order to minimize sampling errors, portions of $\approx 100 \mathrm{~g}$ were prepared for both powders from the received powder packages. All feeding studies were performed using these samples and the used powder was returned to the package. The samples were always kept under vacuum conditions (except for powder withdrawal and return). No experiments were executed when the humidity in the laboratory exceeded $70 \%$. 


\subsection{Micro-Mixing Simulations through DEM-PBM Coupling}

A computational approach was applied to test if the proposed micro feeding system can be incorporated into a continuous powder mixer, i.e., if discrete dosing events (i.e., once per oscillation) can be smoothened by a continuous powder mixer to yield a uniform concentration in a powder stream. The goal of this simulation study was to investigate how fluctuations in the feeding rate affect the content uniformity of low dose blends (i.e., powder mixtures with a relatively low API fraction).

The simulations were performed based on a framework developed by Sen et al. [27][28], in which a DEM model of a continuous powder mixer was coupled with a compartmental population balance model (PBM). This model proved to be robust and in good qualitative agreement with pure DEM simulations [25], which are computationally more expensive.

Discrete Element Method Model

DEM simulations were executed for a continuous Gericke GCM250 (Gerike Holding LTD., Regensdorf, Switzerland) powder mixer with a diameter of $100 \mathrm{~mm}$ and a length of $330 \mathrm{~mm}$. The mixer's impeller consists of a shaft with twelve triangular blades arranged in an alternating forward and backward configuration. The impeller rotated at a speed of $250 \mathrm{rpm}$. Spherical particles with a diameter of $1 \mathrm{~mm}$ were injected into the mixer via the mixer inlet. Two DEM simulations were performed at total particle injection rates of 10,000 particles /s and 5,000 particles /s. All other simulation parameters were kept constant. The Hertz-Mindlin contact model was used to simulate particle-particle and particle-wall interactions. Simulations were run for a total time of $250 \mathrm{~s}$. Due to computational limitations, the DEM simulations were performed using larger particles than those of lactose powders listed in Table 2. The details of the parameters used for the DEM simulations are provided in Table 3.

After the simulations were completed, the DEM model was discretized using the $10 \times 10$ grid-bins in $x$ and $z$ directions, as shown in Figure 2 (a) and (b). The axial and radial average particle velocities were extracted from each of the gridbins at every second. These velocities were averaged over 5 seconds and used as input to the PBM (see Figure 2 c).

Table 3: DEM simulation parameters. Most parameters have been obtained from previous powderblending DEM studies [29].

\begin{tabular}{|l|c|}
\hline \multicolumn{2}{|l|}{ Particle properties } \\
\hline Diameter & $1 \mathrm{~mm}$ \\
\hline Density & $1500 \mathrm{~kg} / \mathrm{m}^{3}$ \\
\hline Shear modulus & $1 \mathrm{MPa}$ \\
\hline Poisson's ratio & 0.33 \\
\hline Mixer wall properties & $8000 \mathrm{~kg} / \mathrm{m}^{3}$ \\
\hline Density & $79.3 \mathrm{GPa}$ \\
\hline Shear modulus & 0.33 \\
\hline Poisson's ratio & \\
\hline Interaction parameters: particle-particle \\
\hline Coefficient of Static Friction & 0.5 \\
\hline Coefficient of Rolling Friction 0 & 0.01 \\
\hline
\end{tabular}




\begin{tabular}{|c|c|}
\hline Coefficient of Restitution 0 & 0.1 \\
\hline \multicolumn{2}{|c|}{ Interaction parameters: particle-mixer wall } \\
\hline Coefficient of Static Friction & 0.4 \\
\hline Coefficient of Rolling Friction & 0.01 \\
\hline Coefficient of Restitution & 0.1 \\
\hline \multicolumn{2}{|l|}{ Total particle injection rates } \\
\hline Simulation 1 & $\begin{array}{c}10,000 \text { particles } / \mathrm{s} \\
\sim 7.9 \mathrm{~g} / \mathrm{s}\end{array}$ \\
\hline Simulation 2 & $\begin{array}{c}5,000 \text { particles } / \mathrm{s} \\
\sim 3.9 \mathrm{~g} / \mathrm{s}\end{array}$ \\
\hline
\end{tabular}

DEM simulations were performed using EDEM ${ }^{\circledR}$ (DEM Solutions, Edinburgh, UK) in a computer with dual Intel ${ }^{\circledR}$ Xeon $^{\circledR}$ E5-2687W $0 @ 3.10 \mathrm{GHz}$ processors and 128 GB RAM.

\section{Compartmental Population Balance Model}

A multidimensional population balance model was applied to simulate mixing of the two materials (API and excipient). The general equation for the model is given by [25]:

$$
\begin{gathered}
\frac{d f}{d t}+\frac{\partial}{\partial x}\left(f \frac{d x}{d t}\right)+\frac{\partial}{\partial z}\left(f \frac{d z}{d t}\right)=\dot{f}_{\text {in }}-\dot{f}_{\text {out }} \\
f=f(n, x, z, t)
\end{gathered}
$$

where $f$ is the number of particles; $n$ is the component number $(n=1$ represents particles of type API and $n=2$ is

particles of type excipient); $x$ and $z$ are spatial coordinates in the axial and radial directions, respectively; $\frac{d x}{d t}$ and $\frac{d z}{d t}$ are the particle velocities in the axial and radial directions, respectively; and $\dot{f}_{\text {in }}$ and $\dot{f}_{\text {out }}$ are rates at which particles enter and exit the mixer, respectively (i.e., $\dot{f}_{\text {in }}>0 / \dot{f}_{\text {out }}>0$ at the mixer's inlet/outlet).

As described above, the PBM was implemented by discretizing the mixer geometry into 10 parts axially and 10 parts along the diameter to form a total of 100 compartments (Figure $2 \mathrm{c}$ ). Average particle velocities obtained from the DEM simulations for each compartment were used as input for the PBM. Particles generated in the compartment model were treated as discrete entities moving forward or backward from one compartment to another. It was assumed that particles in the inlet of the PBM model do not flow backwards. It was also assumed that the particles in the grid-bins at the top end of the blender do not flow upwards and particles in the grid-bins at the bottom end of the blender do not flow downwards. Particles in all other compartments are free to move in all four directions. Mixing was assumed to occur only via convection. Mixing via dispersion was neglected since in a continuous mixer the dispersion rates are much lower than the convection rates [30], i.e., Péclet numbers are high. For more details of the model refer to Sen et al. [27].

In the PBM simulations, the total particle flow rate corresponded to the flow rate in the DEM simulation (e.g., flow rate of 10,000 particles $/ \mathrm{s}$ in the PBM when using the velocity data from the DEM simulation with 10,000 particles $/ \mathrm{s}$ ). In the PBM simulation of a micro-mixing process (e.g., generating a low dose blend via continuous micro feeding into a 
continuous powder mixer), API particles accounted for only $1 \%$ of the total flow rate. Excipient particles represented the rest. API was fed via $\dot{f}(1, x, z, t)_{\text {in }}>0$ into the 10 grid-bins at the left of the discretized mixer geometry. In order to study the effect of feeding variation on the mixing quality, fluctuations were introduced by varying the API feed flow rate as a sine wave. The amplitude of fluctuations was kept at $30 \%$ of the mean API flow rate. Three fluctuation periods were studied: $10 s, 1 s$ and $0.1 s$, with a total of six PBM simulations conducted (three for each flow rate). The quality of mixing was monitored by recording the changes in the total concentration and calculating the RSD (to quantify blend uniformity) of the API at mixer exit using equation 2.

$$
\begin{aligned}
& R S D_{B U}=\frac{\sqrt{\frac{\sum_{Z=1}^{z=10}\left(C_{Z}-C_{\text {avg }}\right)^{2}}{(n-1)}}}{C_{\text {avg }}} \\
& C_{Z}=\frac{f(n=1, x=10, z)}{\sum_{n=1}^{n=2} f(n, x=10, z)} \\
& C_{\text {avg }}=\frac{\sum_{Z=1}^{z=10} C_{Z}}{10}
\end{aligned}
$$

The model is based on the assumption that fluctuations in the API flow rate do not cause a significant change in the average particle velocities since the flow rates of the fed API are very low compared to those of the excipient. In the DEM simulation, the API and excipient particles were assumed to have the same size and material properties.

Since the PBM model requires velocity data from DEM simulations, PBM simulations were run for the same length of time as the DEM $(250 \mathrm{~s})$. The two DEM simulations reached steady state at different times $(10,000 \mathrm{particles} / \mathrm{s}$ simulation at $50 \mathrm{~s}$ and 5,000 particles $/ \mathrm{s}$ simulation at $70 \mathrm{~s}$ ). Taking this into account, the fluctuations in the PBM models were simulated for different times at the two flow rates that maintained the models in steady state and in fluctuating conditions for equal periods of time.

The population balance equation (Equation 1) was discretized using a central finite difference scheme of order 6 . The resulting system of ordinary differential equations was integrated via an implicit backward differential formula (BDF) technique. This model was developed and simulated using gPROMS ${ }^{\mathrm{TM}}$ (Process Systems Enterprise, London, UK).

\section{Results and Discussion}

Both of the investigated powders have a fair flowability (see Table 2 and [31]). In the absence of vibrations of the dosing

unit, powder is not dispensed due to bridging (powder I: $\frac{d_{\text {hole }}}{x_{90}} \sim 5$, powder II: $\frac{d_{\text {hole }}}{x_{90}} \sim 7$ ). Vibration destabilizes the bridging structures and enables powders to flow. When the vibrations stop, the bridge structures are swiftly restored and dispensing stops.

In addition to vibratory settings, the powder filling level in the sieve, the particle size/shape distributions (and powder properties in general) and the number/position of sieve holes are expected to affect the powder dispersion/flow [32][33] and bridging [18] and, ultimately, the feed rate. Sections 3.1-3.3 present experimental studies that investigate 
their effects on micro feeding. Section 3.4 shows the effect of the feeding rate fluctuations on the content uniformity of a low-dose blend, which was determined via a computational approach.

\subsection{Initial Feeding Studies}

Due to the working principle of the feeder and properties of powder I and powder II (see Table 1), size segregation in the sieve had to be considered. To that end, the sieve was filled completely ( $2 g$ for powder I \& II) and the feed rates were analyzed until it was empty. Feeding was performed through holes 1, 3 and 5. Feed rates of powders I and II at the low and high settings (see Table 2) are shown in Figure 3.

While at the low setting feed rates remained robust until the sieve was empty, this was not the case when feeding via high settings, especially for powder I. The experiment was repeated for powder I fed at the high setting, with the same outcome (data not shown here).

The filling level did not affect feed rates using the low settings. Hence, the increase $(>40 s)$ and decrease $(>110 s)$ of the feed rate in Fig. $3 \mathrm{~b}$ is likely associated with a change in powder flow properties caused by feeding at the high setting (e.g., due to size segregation [32] or electrostatic charging [34]).

The initial feeding studies indicated similar feed rates for powders I and II at the low setting $(4.2 \& 3.8 \mathrm{mg} / \mathrm{s})$. However, at the high setting a significant difference was observed $(14.5 \& 25.1 \mathrm{mg} / \mathrm{s})$. To understand this difference, powder flow from the sieve was analyzed using a high-speed camera, as described in Supplementary Information (SI 2: Characterization of Powder Flow from the Sieve). The analysis showed that the frequency of powder dispensing matches the vibration frequency, i.e., powder exits the sieve once per oscillation (15 times per second at the low setting; 80-90 times per second at the high setting). In addition, the videos allowed estimating the time slice powder was exiting the sieve during a single oscillation. SI2 presents a detailed comparison of estimated net feeding times ( $n f t$ [\%]), i.e., the relative amount of time powder actually exits the sieve during feeding. The net feeding times of powder I and powder II were similar for low (7 \% powder I, $6 \%$ powder II) and high settings (18\% powder I, $14 \%$ powder II). Hence, the discrepancy in feed rate difference in the case of high settings cannot be explained by different durations of powder flow and blockage. Recorded videos show that the amount of powder exiting the sieve during the net feeding time was higher in the case of powder II. All videos files (powders I and II, low and high settings, two recordings each, eight videos in total) are provided in the electronic supplementary information.

A detailed analysis to which extent vibratory settings and powder properties account for the different amount of powder dispersed during an oscillation was not an aim of this work. The discrepancy in feed rates at the high settings indicates that powder properties are crucial, since differences in the vibratory settings $(80-90 \mathrm{~Hz})$ were marginal.

\subsection{Single-Hole Feeding}

To study feed rate variations among the sieve holes, single-hole studies were performed for powder I. All of the sieve's holes were blocked except for one. For every single-hole experiments, powder I was fed 10 times for $20 s$ and measured with the lab scale (see Figure 1). Segregation studies (see Section 3.1) showed that the filling level in the 
sieve did not significantly affect the feed rate at the low feeding setting. Also at the high setting, feed rate variations were not expected to be caused by the filling level variations. However, dispensed powder was returned into the sieve to maintain the filling level and to exclude effects of the filling level variations. After $5^{\text {th }}$ feeding, an interim feeding was executed using altered vibration settings to prove that the feed unit's oscillation patterns were reproducible and that equal settings yielded equal feed rates. To determine the feed rate, feeding was analyzed for $17 s$ after the recorded weight exceeded $2 \mathrm{mg}$ (see fraction highlighted in black in Figure 4). A feed rate was assigned to a single hole by averaging the feed rates of all 10 analyzed feedings. The feed rate error was determined via their standard deviation. Figure 4 shows the single hole studies of hole 1 and explains the feed rate evaluation.

Feed rates and standard deviations for low and high setting are shown in Figure 5. The results show that holes near the sieve wall (i.e., hole 1,2) have lower feed rates. This may be due to wall effects [35][36]. The standard deviation (Figure 5) of wall-near holes is the lowest, yielding a stable feeding process.

Since the comparison of feeding characteristics of the first and last five feedings indicated no discrepancies, we assumed that the feed unit's oscillation patterns were reproducible, also after changing the vibratory settings. Details are shown in Supplementary Information (SI 3: Detailed Filling Analysis). However, detailed filling analysis via resampling of fed powders presented in SI indicates that variations in the feed rate are to a great extent due to inconsistent powder properties.

\subsection{Multi-hole Feeding Studies}

The vibratory sieve-chute system allows tuning feed rates via the vibratory settings and the sieve geometry (e.g., sieve dimensions and size and number of sieve holes). This section describes multi-hole feeding studies. Feeding rates were quantified using a sieve with 1 (hole 1), 3 (hole 1, 2,5) and 5 open holes. The holes were selected based on the lowest feed rate error obtained during the detailed filling analysis (see SI 3: Detailed Filling Analysis).

For the experiments with 1, 3 and 5 open holes, powder I and II was fed 6 times for $80 s$ via low and high settings. After the recorded weight exceeded $2 \mathrm{mg}$, feeding was analyzed for $75 \mathrm{~s}$. As before, the filing level was kept constant $(2-$ $3 \mathrm{~g}$ ) to exclude the effects of filling level variations. New powder was added into the sieve after each feeding. The analyzed part of the recorded feeding characteristics and feed rates and their standard deviations are shown in Figure 6.

\section{$\rightarrow$ Figure 6}

While feeding was stable using holes 1 and 3 at the low setting and hole 1 at the high setting, the other the feeding rates were inconsistent, i.e., strong variations were observed. To determine the underlying reason, the collected samples (powder l, high settings, 3 open holes) that had significant feed rate variations ( $12 \mathrm{mg} / \mathrm{s} \& 8 \mathrm{mg} / \mathrm{s}$ ) were analyzed via laser diffraction (see SI 4: Particle Size Analysis of Powders Exhibiting Feeding Rate Variations). The size 
analysis did not indicate major differences in the particle size distribution. However, inconsistent feeding rates were observed at high feeding rates, i.e., at a high powder througput. This suggests that the feed rate variations originated from a change in the properties of the powder that remained in the sieve (or newly-added powder), which is in line with the discussion in Section 3.1.

In order to obtain consistent powder properties, powder I was sieved and separated into two fractions, i.e., 90 $160 \mu \mathrm{m}$ and $90-100 \mu \mathrm{m}$. Micrographs of sieved powder fractions are shown in Figure 7. The sieved powders were used to repeat the feeding studies with 3 open holes. Figure 8 shows the analyzed part of recorded feeding characteristics and the feed rates and their standard deviations.

\section{$\rightarrow$ Figure 7}

\section{$\rightarrow$ Figure 8}

As can be seen, the feed rates of powder I sieved between $90-160 \mu \mathrm{m}$ were more robust than those of the same powder used as received (see Figure 6). The powder fraction sieved between $90-160 \mu \mathrm{m}$ resulted in feed rate variations smaller than $0.1 \mathrm{mg} / \mathrm{s}(\mathrm{RSD}=0.023)$ in the case of low setting and $0.15 \mathrm{mg} / \mathrm{s}(\mathrm{RSD}=0.017)$ for the high setting. Feed rates became even more robust when using the powder fraction sieved between $90-100 \mu m$ as apparent from feed rate variations when feeding at high settings. This is in agreement with the studies shown in section 3.1, where feed rate variations at the high setting were discussed to originate from a change in powder flow properties, for example due to segregation.

Besides the feeding robustness, fine tuning of the feed rates and control over them are important. While powder properties and the number of sieve holes cannot be changed during feeding, feeding rates can easily be manipulated via vibratory settings. Figure 9 shows how changes in the amplitude setting affect the feeding rates, with higher amplitudes giving higher feed rates.

\section{$\rightarrow$ Figure 9}

\subsection{Micro-Mixing Studies}

The coupled model (see Section 2.4) was used to study the effect of API feed fluctuations on the quality of mixing. Figure 10 compares the inlet and outlet concentrations in the mixer during various periods of inlet feed fluctuations $(10 \mathrm{~s}, 1 \mathrm{~s}$ and $0.1 \mathrm{~s})$ at total feeding rates of 10,000 particles $/ \mathrm{s}$ (excipient feeding rate $\approx 7.9 \mathrm{~g} / \mathrm{s}$, API feeding rate $\approx$ $79 \mathrm{mg} / \mathrm{s}$ ) and with 5,000 particles $/ \mathrm{s}$ (excipient feeding rate $\approx 3.9 \mathrm{~g} / \mathrm{s}$, API feeding rate $\approx 39 \mathrm{mg} / \mathrm{s}$ ). For API feeding rate fluctuations of $1 \mathrm{~s}$ and $0.1 \mathrm{~s}$, changes in the blender exit concentration were hardly noticeable. Fluctuations in the concentration were observed at the mixer's outlet during the $10 \mathrm{~s}$ simulations. The amplitude of these fluctuations was significantly smaller and did not deviate more than $4 \%$ from the mean at both flow rates, 
although the inlet flow rate oscillated at an amplitude of $30 \%$ about the mean. With regard to RSD at the blender exit (Figure 11), RSD variations are not noticeable at the API feeding rate fluctuations of $1 s$ and $0.1 s$ at both of the excipient feeding rates. RSD fluctuations (determined for intervals of $10 \mathrm{~s}$ ) were higher for the simulation with 10,000 particles/s, although the maximum RSD had a very low value of $0.26 \%$. Hence, the mixer's output can be considered well-mixed (or well dispersed) [37] at both flow rates.

\section{$\rightarrow$ Figure 10}

$\rightarrow$ Figure 11

\section{Summary and Conclusions}

In this work, a vibratory sieve-chute system that can be operated at various frequencies and amplitudes was examined for use as continuous micro feeder into a continuous powder mixer. Such a micro feeder can be used to dose a small amount of API periodically into an excipient stream. Using simple equipment, robust feeding of two lactose powders was performed at feed rates $<1.5 \mathrm{mg} / \mathrm{s}(\mathrm{RSD}<0.08)$. Such low feed rates have been reported only for vibrating capillaries (see Table 1). Up until now, most studies on feeding/dosing via vibrating capillaries do not address continuous feeding applications or feed rate robustness. Due to the simple feeding principle that we applied, the correlation between the feeding rate and the vibratory frequency is monotonous (the higher the frequency, the higher the feed rate) and does not require complex control strategies that involve neural networks or model predictive control. Feeding rates were known to depend on the powder properties, the number of sieve holes (and their size - not studied here) and the vibratory settings (i.e., vibration frequency and amplitude). The latter can be used for fine-tuning the feeding rates but not for coarse adjustments since constant and reproducible feeding can only be achieved within a limited range of frequency and amplitude settings [14]. Hence, a feed rate adjustment may begin with the selection of open sieve holes, followed by the tuning of vibratory settings.

Powder properties have a considerable effect on the feeding robustness. Our feeding experiments at a high powder throughput (e.g., higher feeding rates achieved via higher vibrations) had inconsistent feeding rates. It was shown that robust feeding can be achieved using sieved powders (see Table 4).

Table 4: RSD of feeding rate when powder I was fed as received and sieved with 3 open holes at high and low settings (see Table 2).

\begin{tabular}{|c|c|c|c|c|c|c|}
\cline { 2 - 7 } \multicolumn{2}{c|}{} & \multicolumn{2}{l|}{ Powder I as received } & \multicolumn{2}{l|}{ Powder / sieved $(\mathbf{9 0}-\mathbf{1 6 0} \mu \mathrm{m})$} & \multicolumn{2}{l|}{ Powder / sieved (90-1 00 $\mu \mathrm{m})$} \\
\cline { 2 - 7 } & high & low & high & low & high & low \\
\hline RSD & 0.14 & 0.06 & 0.06 & 0.02 & 0.02 & 0.02 \\
\hline
\end{tabular}


Powder filling-levels in the sieve appeared to have no significant effect on the feeding rates. This implies that the described feeding system can maintain a constant feed rate even if powder is added stepwise. Therefore, the vibratory sieve-chute system can be combined with a classical feeding system (feeding at higher feed rates, but not permanently) to allow continuous micro-feeding, e.g., to generate a low dose blend.

Micro feeding was also studied with a compartment model based on DEM simulation results. The model predicted a satisfactory content uniformity at the end outlet of a continuous powder mixer (Gerike GCM250) into which $99 \%$ excipient and $1 \%$ API were fed. Since feed rate fluctuations are typical for vibration-assisted powder feeders, content uniformity of a fluctuating micro feed was examined. The model predicted that feed-rate fluctuations $<1 s$ (which is also the detection frequency of the dynamic scale used in this work) do not cause poor blend uniformity due to the low-pass filter characteristics of the continuous mixer. In addition the experiments show that feed rates of the studied micro feeder do not depend on the sieve filling level. This facilitates a feeding concept, where the vibrating sieve is intermittently refilled (see SI 5: Feeding concept for low dose blends). Thus, the proposed vibratory sieve-chute system allows continuous micro-feeding relevant to the pharmaceutical production of low-dose blends.

Different drug products have different potency. The dosage uniformity or content uniformity (CU) is the only concern for the patients, as they are consuming the final dosage form and not samples from the blend. However, blend uniformity (BU) data can provide information about batch uniformity and thus, batch-to-batch variability. As discussed in [38], assessment and validation should optimally be performed separately on powder blend uniformity, the inprocess dosage units, and on the finished product. Therefore, the FDA proposed in 2003 acceptance criteria:

1. Assay one sample ( $n$ ) per location, $n \geq 10$;

2. RSD of all individual results $\leq 5 \%$;

3. All individual results within $10 \%$ of the mean

These criteria are described in the "Guidance for Industry Powder Blends and Finished Dosage Units-Stratified InProcess Dosage Unit Sampling and Assessment". The FDA withdrew this draft guidance document on August 7, 2013 since Section V (Exhibit/Validation Batch Powder Mix Homogeneity) and Section VII (Routine Manufacturing Batch Testing Methods) were no longer consistent with their current thinking. For example because described blend uniformity testing lacks confidence and one-time passing of the criteria stated in "USP General Chapter <905> Uniformity of Dosage Units" is not sufficient to ensure the content uniformity of a batch [39][40]. New recommendations of the Blend and Content Uniformity Group (formed in August 2013 and sponsored by the International Society for Pharmaceutical Engineering) are presented in a recent paper [40]. These modifications to the withdrawn guideline are of special interest for HPAPIs and present a framework for the assessment of blend and content uniformity that provides greater assurance of passing USP $<905>$ [40]. The latter paper states that any approach used to demonstrate uniformity of powder blends should be science- and risk-based and that many approaches can be used with justification. This might include a computational approach as presented in this study.

The results of our work can be summarized as follows: 
- A review of micro feeders (i.e., feeding $<10 \mathrm{mg} / \mathrm{s}$ ) and feeding principles and a summary of current regulations concerning blend uniformity for pharmaceutical production was presented.

- A simple feeding principle, i.e., gravimetric powder feeding via a vibratory sieve mounted on a chute, was shown to provide robust feeding even for feed rates below $1.5 \mathrm{mg} / \mathrm{s}$.

- However, robust feeding was achieved only for sieved powders. When using the high-vibratory settings (80 $90 \mathrm{~Hz}$ ) the powders had to be sieved between $90-100 \mu \mathrm{m}$ to achieve robust feeding. In the case of the low vibratory setting $(15 \mathrm{~Hz})$ sieving between $90-160 \mu \mathrm{m}$ was sufficient.

- Feed rates were shown to increase monotonically (not linearly) with vibratory frequency. Different powder properties can lead to significant variations in feed rate, especially when using high settings.

- A computational approach using DEM-PBM coupling was used to study the incorporation of the proposed micro feeding system into a continuous powder mixer for the generation of a low-dose blend (99\% excipient, $1 \%$ API). The model showed that intermittent feeding, which is a characteristic of the proposed micro feeding system, has no influence on API concentration and content uniformity of the low dose blend when occurring with a frequency $<1 \mathrm{~s}$. This is because of the low-pass filter characteristics of the continuous powder mixer.

\section{Acknowledgements}

Research Center Pharmaceutical Engineering is funded by the Austrian COMET Program under the auspices of the Austrian Federal Ministry of Transport, Innovation and Technology (BMVIT), the Austrian Federal Ministry of Economy, Family and Youth (BMWFJ) and by the Province of Styria (Styrian Business Promotion Agency, SFG). COMET is managed by the Austrian Research Promotion Agency, FFG.

The authors would like to thank Hanna Besenhard and Silvia Gemelli for image processing and video analysis as well as Daniel Treffer (MeltPrep.com, Graz, Austria) for his support with the experimental set-up and Michael Piller (RCPE, Graz, Austria) for the execution of particle size analysis. The authors particularly like to thank Stefano Biserni and Riccardo Cova (both MG2, Bologna, Italy) for technical support, as well as Maitraye Sen (Purdue University, West Lafayette, USA) for helpful discussions about the computational approaches. 


\section{Nomenclature}

\begin{tabular}{|c|c|}
\hline Abbrev & \\
\hline A & Amplitude \\
\hline AoR & Angle of Repose \\
\hline API & Active Pharmaceutical Ingredient \\
\hline AR & Aspect Ratio \\
\hline $\mathrm{BD}$ & Bulk Density \\
\hline BDF & Backward Differential Formula \\
\hline BU & Blend Uniformity \\
\hline $\mathrm{CI}$ & Carr Index \\
\hline $\mathrm{CU}$ & Content Uniformity \\
\hline$\overline{\mathrm{DEM}}$ & Discrete Element Method \\
\hline $\mathrm{E}$ & Entities (amplitude unit) \\
\hline $\mathrm{F}$ & Frequency \\
\hline HPAPI & High-Potency Active Pharmaceutical Ingredients \\
\hline PBM & Population Balance Model \\
\hline PSD & Particle Size Distribution \\
\hline RSD & Relative Standard Deviation \\
\hline R.H. & Relative Humidity \\
\hline SV & Sieved \\
\hline TD & Tapped Density \\
\hline USP & United States Pharmacopeia \\
\hline
\end{tabular}




\begin{tabular}{|c|c|}
\hline Symbols & \\
\hline $\mathrm{X}_{10}, \mathrm{X}_{50}, \mathrm{X}_{90}$ & 10,50 and $90 \%$ of the PSD reside below the particle size $x$ \\
\hline $\mathrm{F}_{\min }, \mathrm{F}_{\max }$ & Minimum and maximum Feret diameters \\
\hline$d_{\text {hole }}$ & Sieve hole diameter (all hole are of the same size) \\
\hline$f$ & Number of particles \\
\hline$a$ & (vertical) Acceleration of the sieve \\
\hline$t$ & Time \\
\hline$n$ & Component number $(n=1 \equiv$ API; $n=2 \equiv$ Excipient $)$ \\
\hline$x, \mathrm{y}$ & Spatial coordinates in axial and radial directions respectively \\
\hline$\dot{f}_{\text {in }}$ & Rates of particles entering the mixer \\
\hline$\dot{f}_{\text {in }}$ & Rate of particles exiting the mixer \\
\hline$f r$ & Feeding rate \\
\hline$n f r$ & Net feeding rate (i.e., the relative amount of time powder actually exits the sieve) \\
\hline
\end{tabular}




\section{References}

[1] S. Mehrotra, "High Potency Active Pharmaceutical Ingredients (HPAPIs): The fastest growing market segment in the pharmaceutical industry," Chim. Oggi, vol. 28, no. 5, pp. 43-45.

[2] D. Edwards, "Applications of capsule dosing techniques for use in dry powder inhalers.," Ther. Deliv., vol. 1, no. 1, pp. 195-201, Jul. 2010.

[3] E. Faulhammer, M. Fink, M. Llusa, S. M. Lawrence, S. Biserni, V. Calzolari, and J. G. Khinast, "Low-dose capsule filling of inhalation products: critical material attributes and process parameters," Int. J. Pharm., vol. 473, no. 1-2, pp. 617-626, 2014.

[4] M. Bi, C. C. Sun, F. Alvarez, and F. Alvarez-Nunez, "The manufacture of low-dose oral solid dosage form to support early clinical studies using an automated micro-filing system.," AAPS

PharmSciTech, vol. 12, no. 1, pp. 88-95, Mar. 2011.

[5] J. Zheng, Formulation and Analytical Development for Low- Dose Oral Drug Products, 1st ed. Hoboken: John Wiley \& Sons, 2009.

[6] Z. K. Nagy and R. D. Braatz, "Advances and new directions in crystallization control.," Annu. Rev. Chem. Biomol. Eng., vol. 3, pp. 55-75, Jan. 2012.

[7] M. O. Besenhard, P. Neugebauer, C. Da-Ho, and J. G. Khinast, "Crystal Size Control in a Continuous Tubular Crystallizer," Cryst. Growth Des., vol. 15, no. 4, pp. 1683-191, Jan. 2015.

[8] and V. H. Timothy Noël, Yuanhai Su, "Beyond Organometallic Flow Chemistry: The Principles Behind the Use of Continuous- Flow Reactors for Synthesis," in Topics in Organometallic Chemistry, 1st ed., Heidelberg: Springer Berlin Heidelberg, 2015, pp. 1-41.

[9] A.-K. Liedtke, F. Scheiff, F. Bornette, R. Philippe, D. W. Agar, and C. de Bellefon, "Liquid-Solid Mass Transfer for Microchannel Suspension Catalysis in Gas-Liquid and Liquid-Liquid Segmented Flow," Ind. Eng. Chem. Res., vol. 54, no. 17, pp. 4699-4708, May 2015.

[10] M. O. Besenhard, A. Thurnberger, R. Hohl, E. Faulhammer, J. Rattenberger, and J. G. Khinast, "Continuous API-crystal coating via coacervation in a tubular reactor.," Int. J. Pharm., vol. 475, no. 1-2, pp. 198-207, Aug. 2014.

[11] A. Levy and H. Kalman, Handbook of Conveying and Handling of Particulate Solids, Volume 10. Amsterdam: Elsevier Science, 2001.

[12] H. Masuda, K. Higashitani, and H. Yoshida, Powder technology handbook, 3rd ed. Boca Raton: Taylor \& Francis Group, 2006.

[13] G. Vetter, Handbuch Dosieren, 2nd ed. Essen: Vulkan-Verl., 2001.

[14] M. O. Besenhard, E. Faulhammer, S. Fathollahi, G. Reif, V. Calzolari, S. Biserni, A. Ferrari, S. M. Lawrence, M. Llusa, and J. G. Khinast, "Accuracy of micro powder dosing via a vibratory sievechute system.," Eur. J. Pharm. Biopharm., vol. 94, pp. 264-272, Jun. 2015.

[15] S. Yang and J. R. G. Evans, "Computer control of powder flow for solid freeforming by acoustic modulation," Powder Technol., vol. 133, no. 1-3, pp. 251-254, Jul. 2003. 
[16] S. Yang and J. R. G. Evans, "Metering and dispensing of powder; the quest for new solid freeforming techniques," Powder Technol., vol. 178, no. 1, pp. 56-72, Sep. 2007.

[17] X. Lu, S. Yang, and J. R. G. Evans, "Studies on ultrasonic microfeeding of fine powders," J. Phys. D. Appl. Phys., vol. 39, no. 11, pp. 2444-2453, Jun. 2006.

[18] G. T. Jasion, J. S. Shrimpton, Z. Li, and S. Yang, "On the bridging mechanism in vibration controlled dispensing of pharmaceutical powders from a micro hopper," Powder Technol., vol. 249, pp. 24-37, Nov. 2013.

[19] X. Chen, K. Seyfang, and H. Steckel, "Development of a micro dosing system for fine powder using a vibrating capillary. Part 1: the investigation of factors influencing on the dosing performance.," Int. J. Pharm., vol. 433, no. 1-2, pp. 34-41, Aug. 2012.

[20] L. Qi, X. Zeng, J. Zhou, J. Luo, and Y. Chao, "Stable micro-feeding of fine powders using a capillary with ultrasonic vibration," Powder Technol., vol. 214, no. 2, pp. 237-242, Dec. 2011.

[21] S. Matsusaka, K. Yamamoto, and H. Masuda, "Micro-feeding of a fine powder using a vibrating capillary tube," Adv. Powder Technol., vol. 7, no. 2, pp. 141-151, Jan. 1996.

[22] X. Lu, S. Yang, and J. R. G. Evans, "Ultrasound-assisted microfeeding of fine powders," Particuology, vol. 6, no. 1, pp. 2-8, Feb. 2008.

[23] T. Horio, M. Yasuda, and S. Matsusaka, "Effect of particle shape on powder flowability of microcrystalline cellulose as determined using the vibration shear tube method.," Int. J. Pharm., vol. 473, no. 1-2, pp. 572-8, Oct. 2014.

[24] A. J. Hickey and N. M. Concessio, "Flow Properties of Selected Pharmaceutical Powders from a Vibrating Spatula," Part. Part. Syst. Charact., vol. 11, no. 6, pp. 457-462, Dec. 1994.

[25] M. Barati Dalenjan, E. Jamshidi, and H. Ale Ebrahim, "A screw-brush feeding system for uniform fine zinc oxide powder feeding and obtaining a homogeneous gas-particle flow," Adv. Powder Technol., vol. 26, no. 1, pp. 303-308, Jan. 2015.

[26] P. Kumar, J. K. Santosa, E. Beck, and S. Das, "Direct-write deposition of fine powders through miniature hopper-nozzles for multi-material solid freeform fabrication," Rapid Prototyp. J., vol. 10, no. 1, pp. 14-23, Feb. 2004.

[27] M. Sen and R. Ramachandran, "A multi-dimensional population balance model approach to continuous powder mixing processes," Adv. Powder Technol., vol. 24, no. 1, pp. 51-59, 2013.

[28] M. Sen, R. Singh, A. Vanarase, J. John, and R. Ramachandran, "Multi-dimensional population balance modeling and experimental validation of continuous powder mixing processes," Chem. Eng. Sci., vol. 80, pp. 349-360, 2012.

[29] M. Sen, A. Dubey, R. Singh, and R. Ramachandran, "Mathematical Development and Comparison of a Hybrid PBM-DEM Description of a Continuous Powder Mixing Process," J. Powder Technol., vol. 2013, pp. 1-11, 2013.

[30] P. M. Portillo, F. J. Muzzio, and M. G. lerapetritou, "Using Compartment Modeling to Investigate Mixing Behavior of a Continuous Mixer," J. Pharm. Innov., vol. 3, no. 3, pp. 161-174, Jun. 2008. 
[31] F. Boschini, V. Delaval, K. Traina, N. Vandewalle, and G. Lumay, "Linking flowability and granulometry of lactose powders.," Int. J. Pharm., vol. 494, no. 1, pp. 312-320, Aug. 2015.

[32] X. Fu, D. Huck, L. Makein, B. Armstrong, U. Willen, and T. Freeman, "Effect of particle shape and size on flow properties of lactose powders," Particuology, vol. 10, no. 2, pp. 203-208, Apr. 2012.

[33] S. V. Søgaard, T. Pedersen, M. Allesø, J. Garnaes, and J. Rantanen, "Evaluation of ring shear testing as a characterization method for powder flow in small-scale powder processing equipment.," Int. J. Pharm., vol. 475, no. 1-2, pp. 315-23, Nov. 2014.

[34] S. Matsusaka, H. Maruyama, T. Matsuyama, and M. Ghadiri, "Triboelectric charging of powders: A review," Chem. Eng. Sci., vol. 65, no. 22, pp. 5781-5807, Nov. 2010.

[35] P. Xu, X. Duan, G. Qian, and X.-G. Zhou, "Dependence of wall stress ratio on wall friction coefficient during the discharging of a 3D rectangular hopper," Powder Technol., vol. 284, pp. 326335, Nov. 2015.

[36] G. Léonard and N. Abatzoglou, "Lubrication of pharmaceutical powder/wall interfaces and electrostatic effects," Powder Technol., vol. 208, no. 1, pp. 54-62, Mar. 2011.

[37] J. G. Osorio, G. Stuessy, G. J. Kemeny, and F. J. Muzzio, "Micro-mixing dynamics of active pharmaceutical ingredients in bin-blending," Chem. Eng. Process. Process Intensif., vol. 102, pp. 141-155, Apr. 2016.

[38] T. Yin, "A guide to blend uniformity," Journal of GXP Compliance, vol. 12, no. 1. pp. 46-51, 2007.

[39] J. Bergum, J. Prescott, R. Tejwani, T. Garcia, J. Clark, and W. Brown, "Current Events in Blend and Content Uniformity," Pharm. Eng. Mag. ISPE, vol. 34, no. 2, pp. 1-10, 2014.

[40] T. Garcia, J. Bergum, J. Prescott, R. Tejwani, T. Parks, J. Clark, W. Brown, F. Muzzio, S. Patel, and C. Hoiberg, "Recommendations for the Assessment of Blend and Content Uniformity: Modifications to Withdrawn FDA Draft Stratified Sampling Guidance," J. Pharm. Innov., vol. 10, no. 1, pp. 76-83, Dec. 2014. 


\section{Figures}

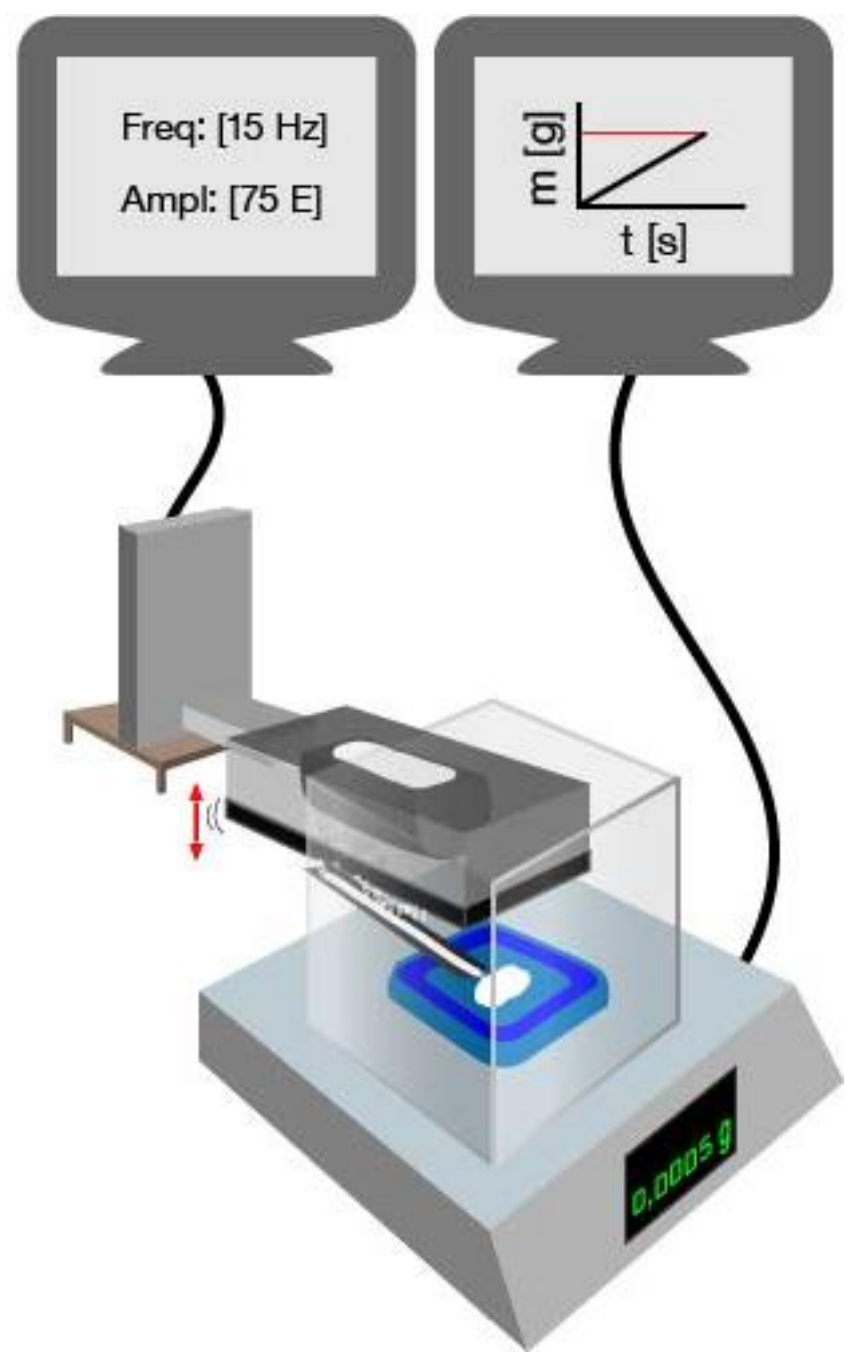

Figure 1: Experimental set-up for studying the feeding characteristics of the vibratory-sieve chute system. 


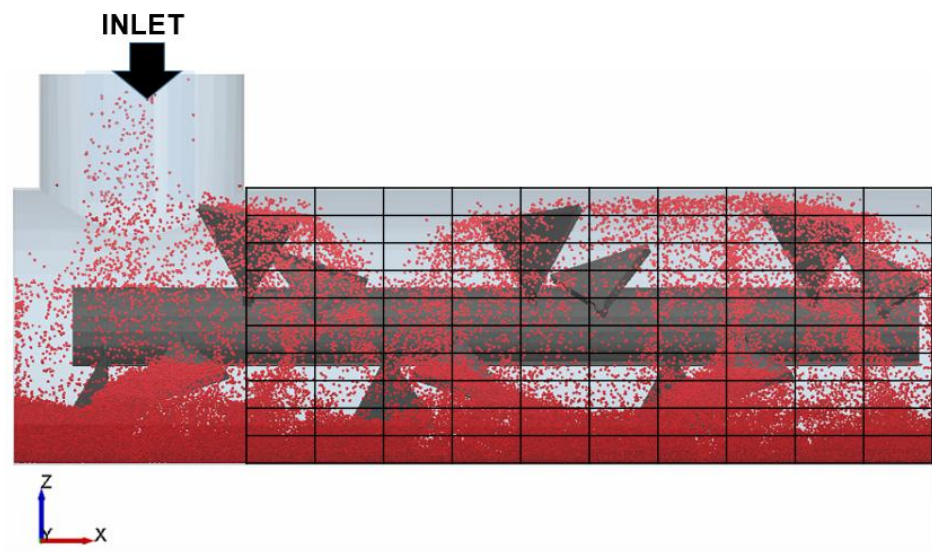

a

INLET

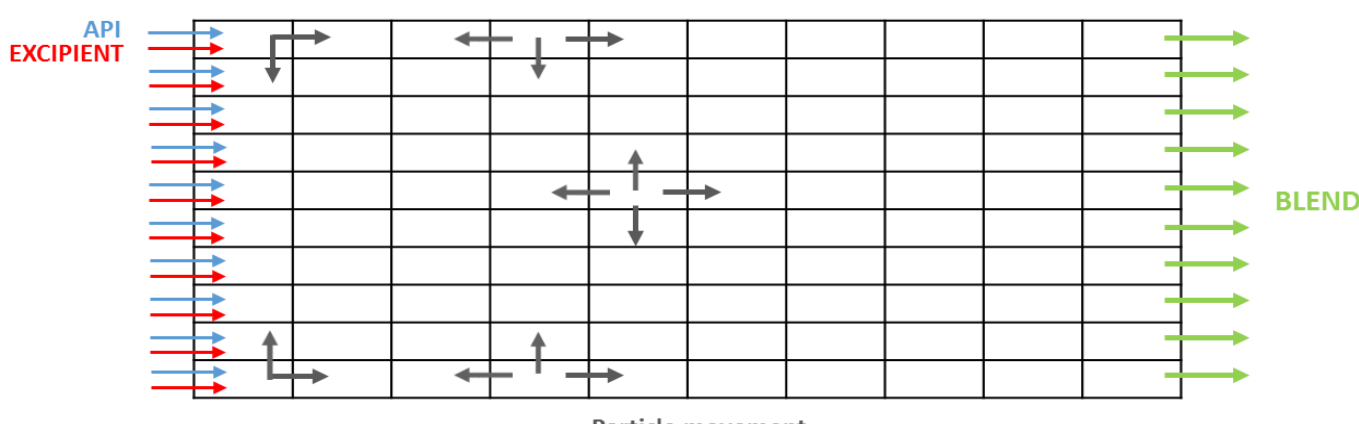

Figure 2: (a) Front view of the continuous mixer model simulated with DEM (particle injection rate $10,000 \mathrm{particles} / \mathrm{s}$ ) with the $10 \times 10$ discretization grid-bins (=compartments). The arrows depict the inlet of particles for the DEM simulations (excipient inlet) and the inlet (i.e., source term) of API used in the PBM compartment. (b) Side view of the mixer with the discretization grid. (c) Discretization of the PB model with inlet, outlet and assumed particle movements. 


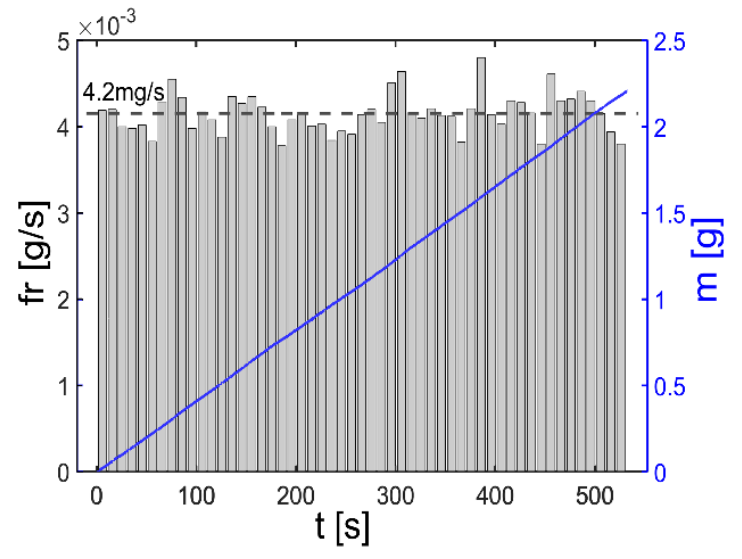

a

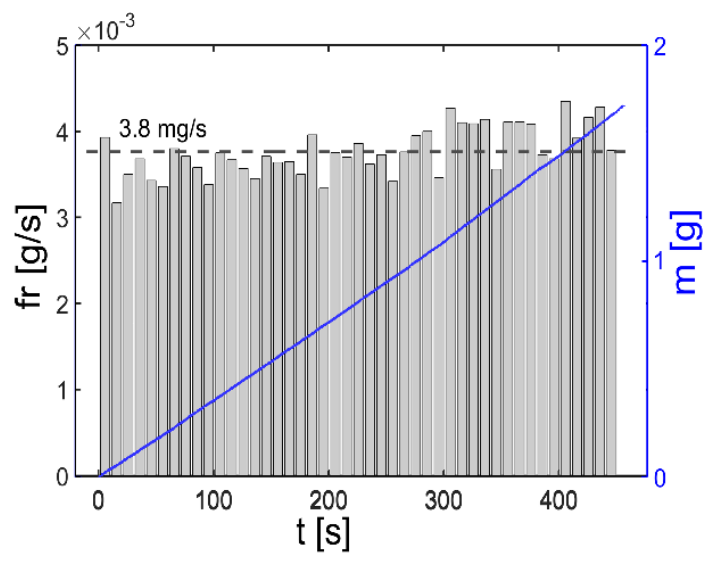

c

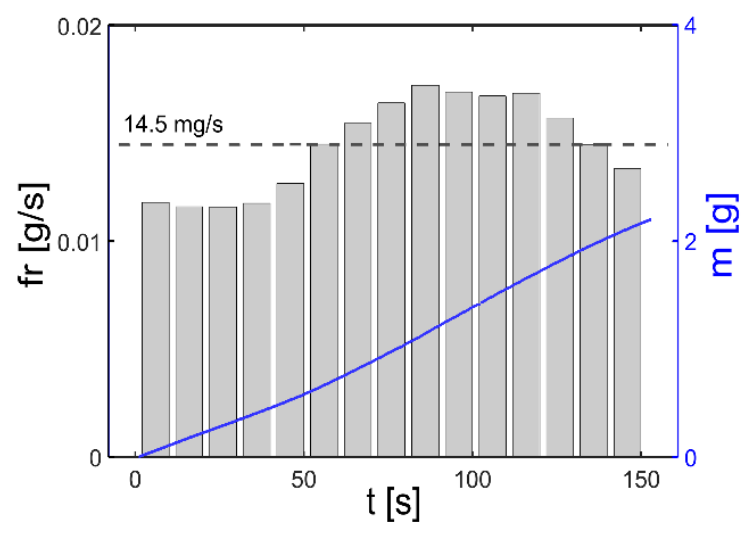

b

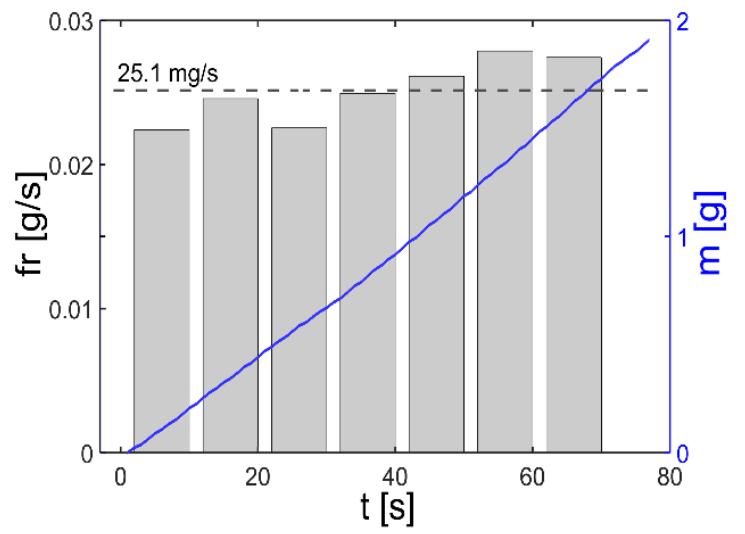

d

Figure 3: Feeding characteristics when no powder is added into the sieve during feeding. The solid line denotes accumulated mass on the scale $(m[g])$ and the bar graph shows the respective feed rate $(f r[g / s])$ averaged over $10 \mathrm{~s}$ : (a) powder I low setting, (b) powder I high setting, (c) powder II low setting and (d) powder II high setting. 


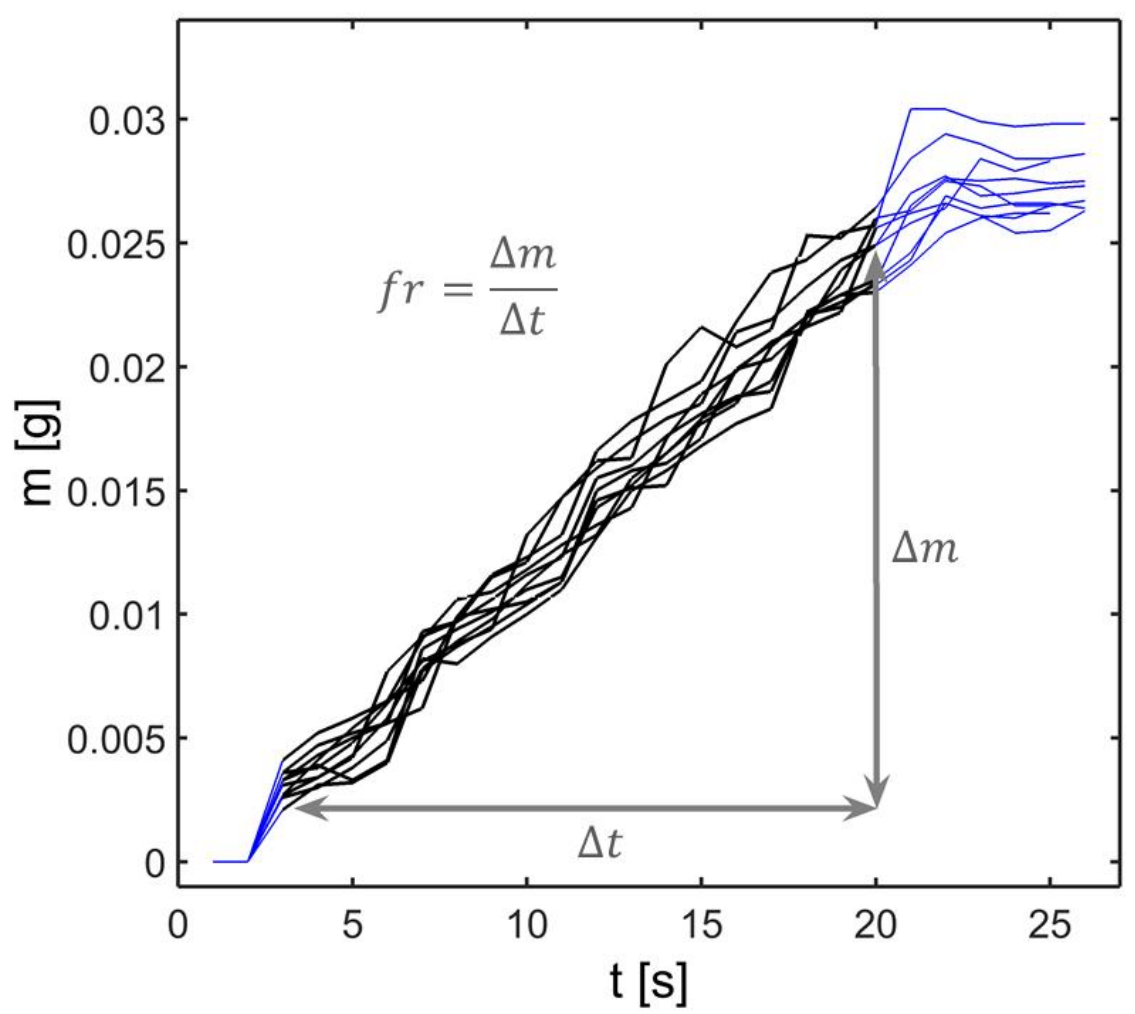

Figure 4: Single-hole study of powder I. The feed rate was determined based on the fraction highlighted in black. Reproducible feeding characteristics: hole 1 , low setting, $f r=1.27 \pm 0.08 \mathrm{mg} / \mathrm{s}$. 

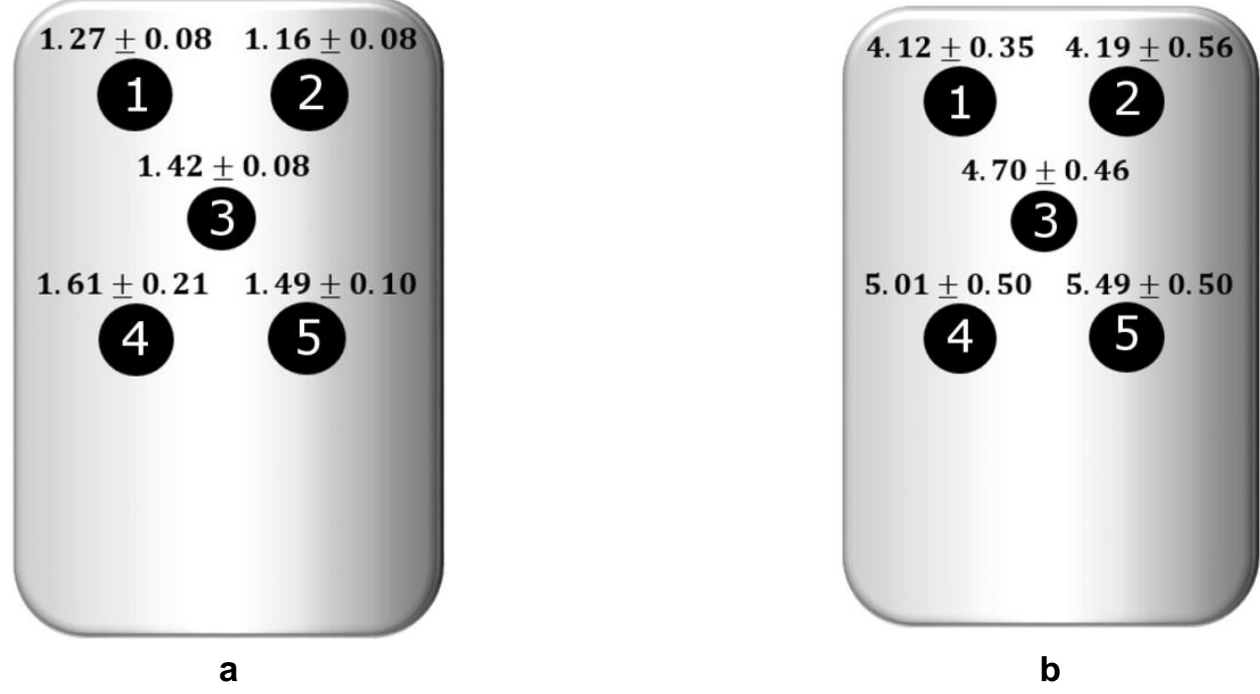

Figure 5: Feed rates and standard deviations (i.e., assigned error values) of powder I fed at (a) low setting and (b) high setting through a single hole. The white numbers denote the holes. 


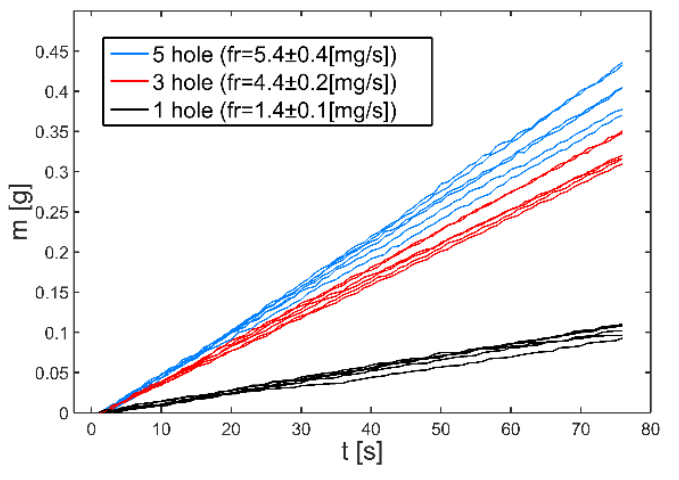

a

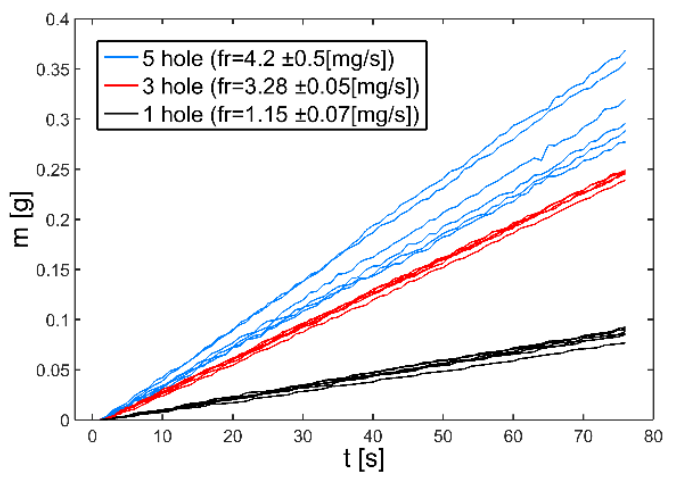

C

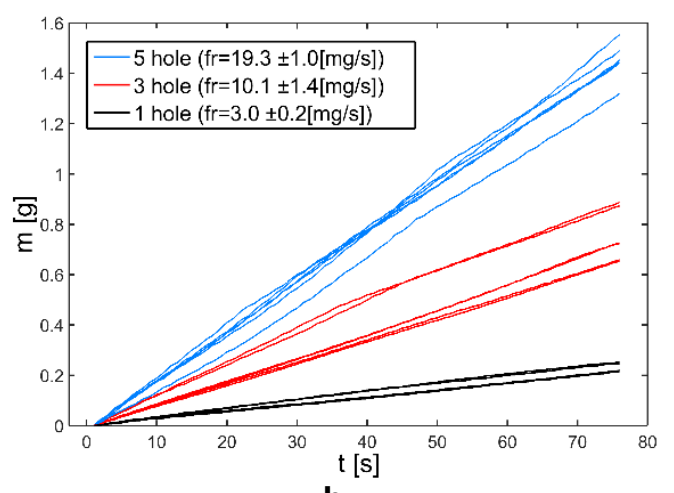

b

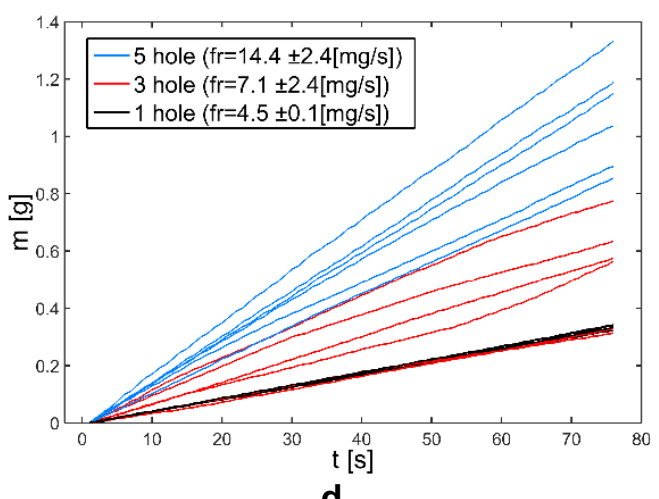

d

Figure 6: Feeding characteristics using various number of holes: (a) powder I, low setting (b) powder I, high setting (c) powder II, low setting and (d) powder II, high setting. 


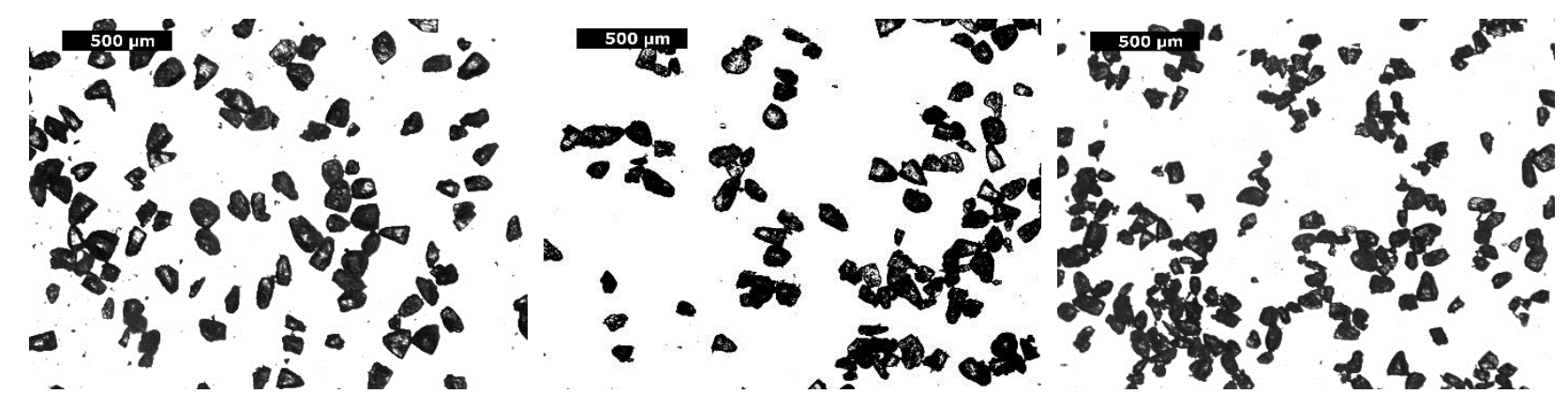

a

b

C

Figure 7: Microscope images of powder I: (a) unsieved (as received), (b) sieved between $90-160 \mu \mathrm{m}$ and (c) sieved between $90-100 \mu \mathrm{m}$. 

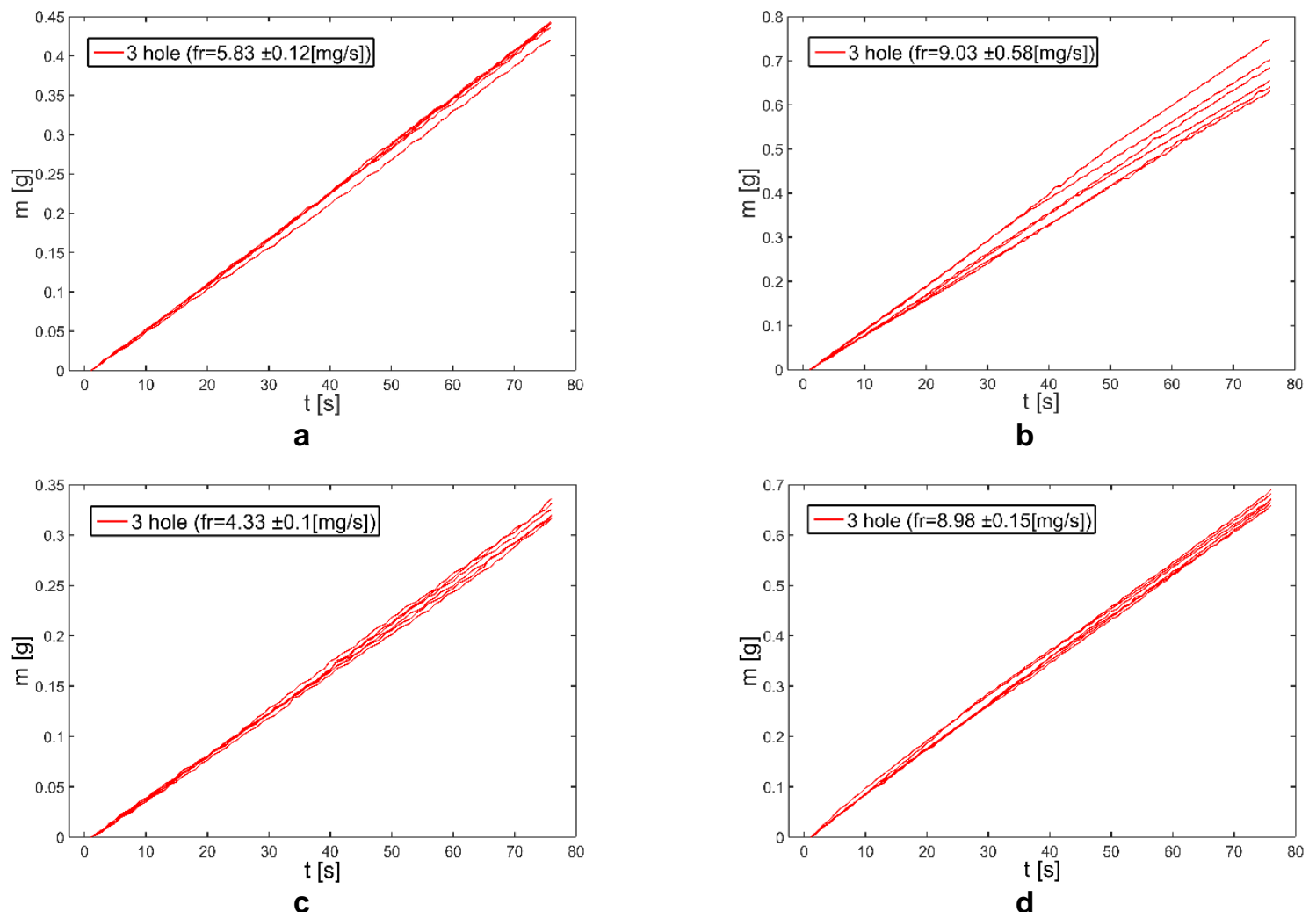

Figure 8: Feeding characteristics sieved powder I for three holes: (a) low setting, sieved to $90-160 \mu \mathrm{m}$, (b) high setting, sieved to $90-160 \mu \mathrm{m}$, (c) low setting, sieved to $90-100 \mu \mathrm{m}$ and (d) high setting, sieved to $90-$ $100 \mu \mathrm{m}$. 


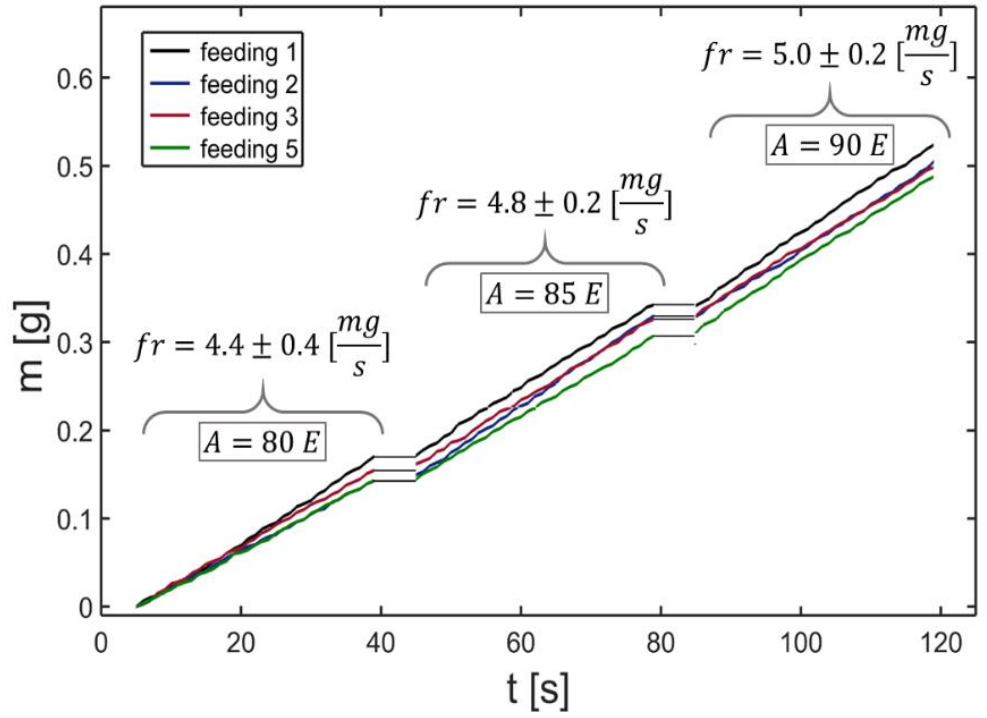

Figure 9: Feed rates for different amplitudes $(5-40 s, 80 E ; 45-80 s, 85 E ; 85-120 s, 90 E)$. Feeding was performed as shown in Figure 8 (powder I sieved, $90-100 \mu \mathrm{m}$ ). 


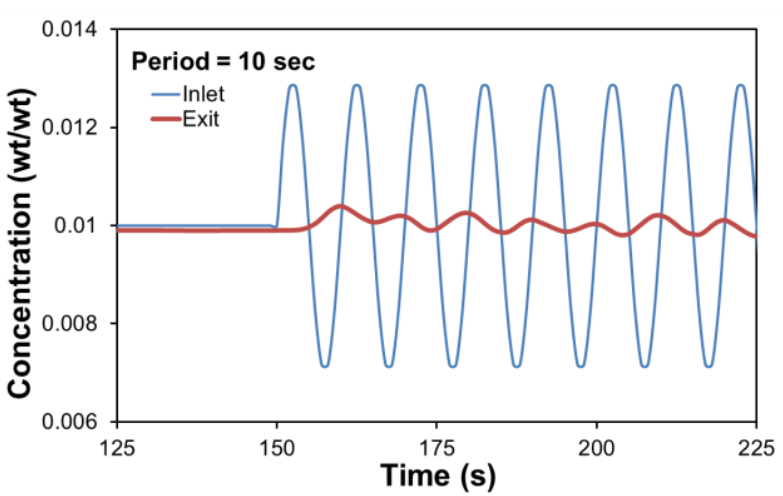

a

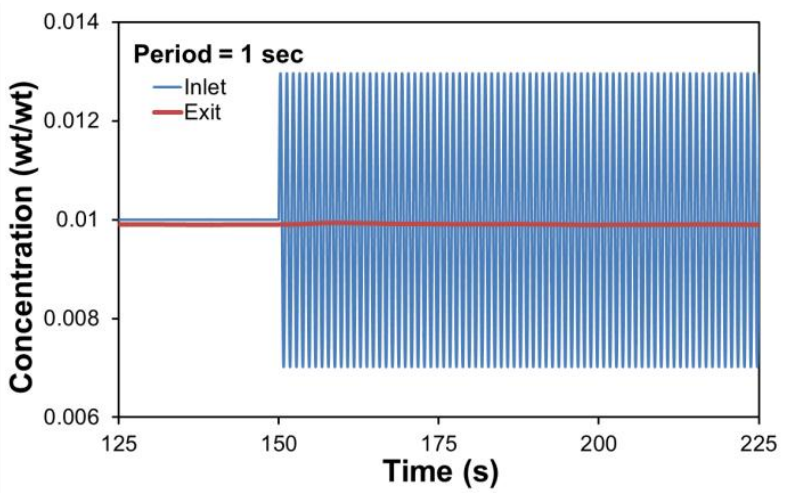

b

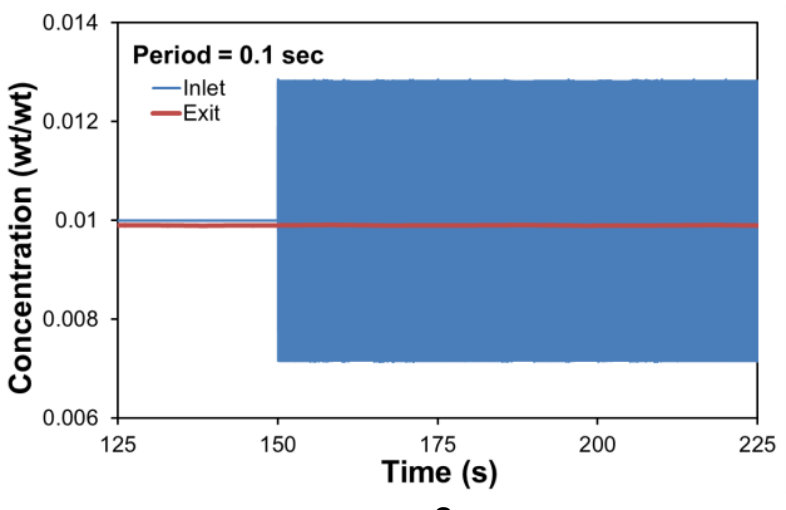

C
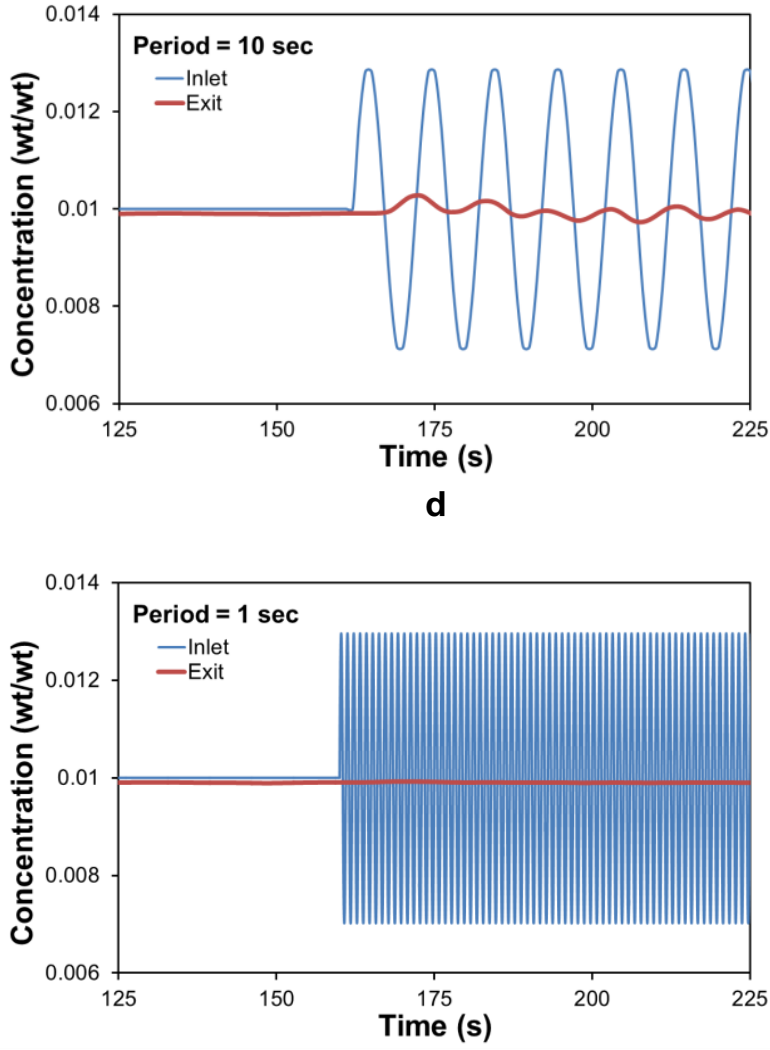

e

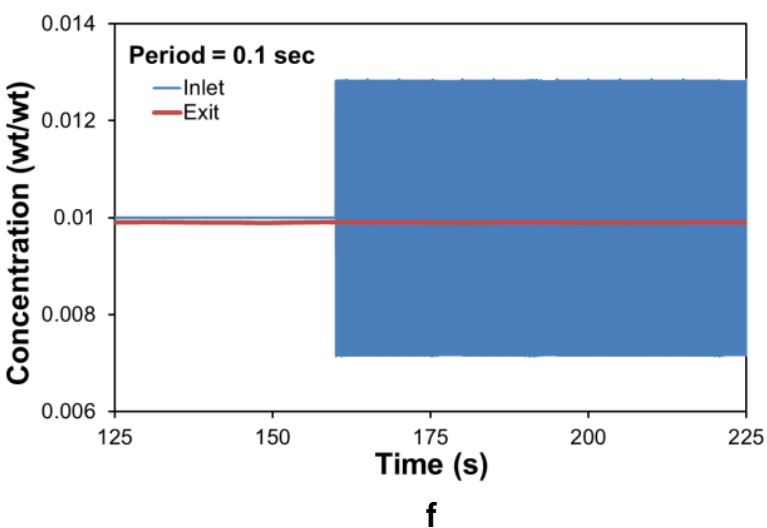

Figure 10: (a), (b) and (c): API concentrations at the inlet and exit of the mixer at a feed rate of 10,000 particles $/ s$ per a period of fluctuations of $10 s, 1 s$ and $0.1 s$, respectively. (d), (e) and (f): API concentrations at inlet and exit of the mixer at a feed rate of 5,000 particles $/ \mathrm{s}$ per a period of fluctuations of $10 \mathrm{~s}$, $1 s$ and $0.1 s$, respectively 


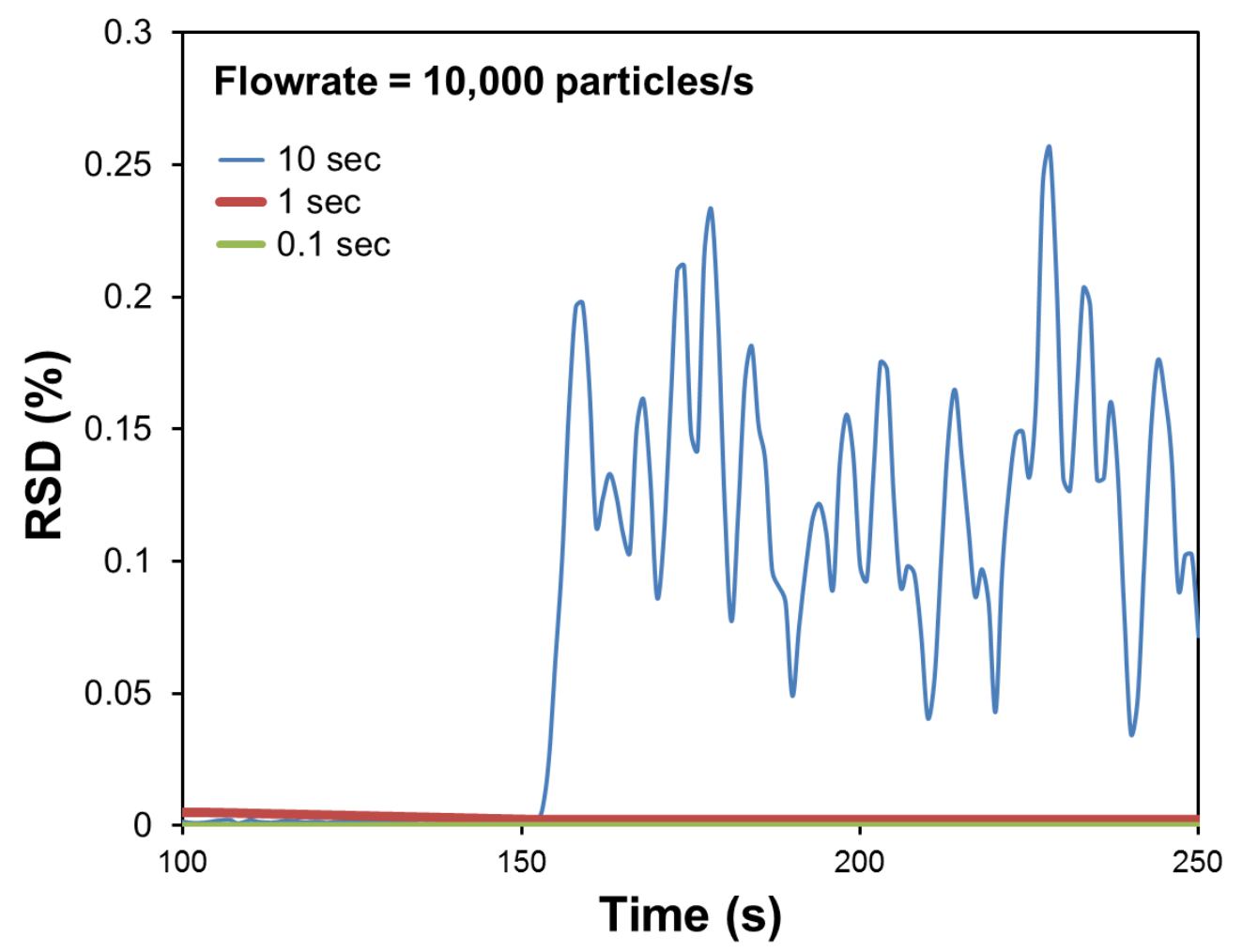

a

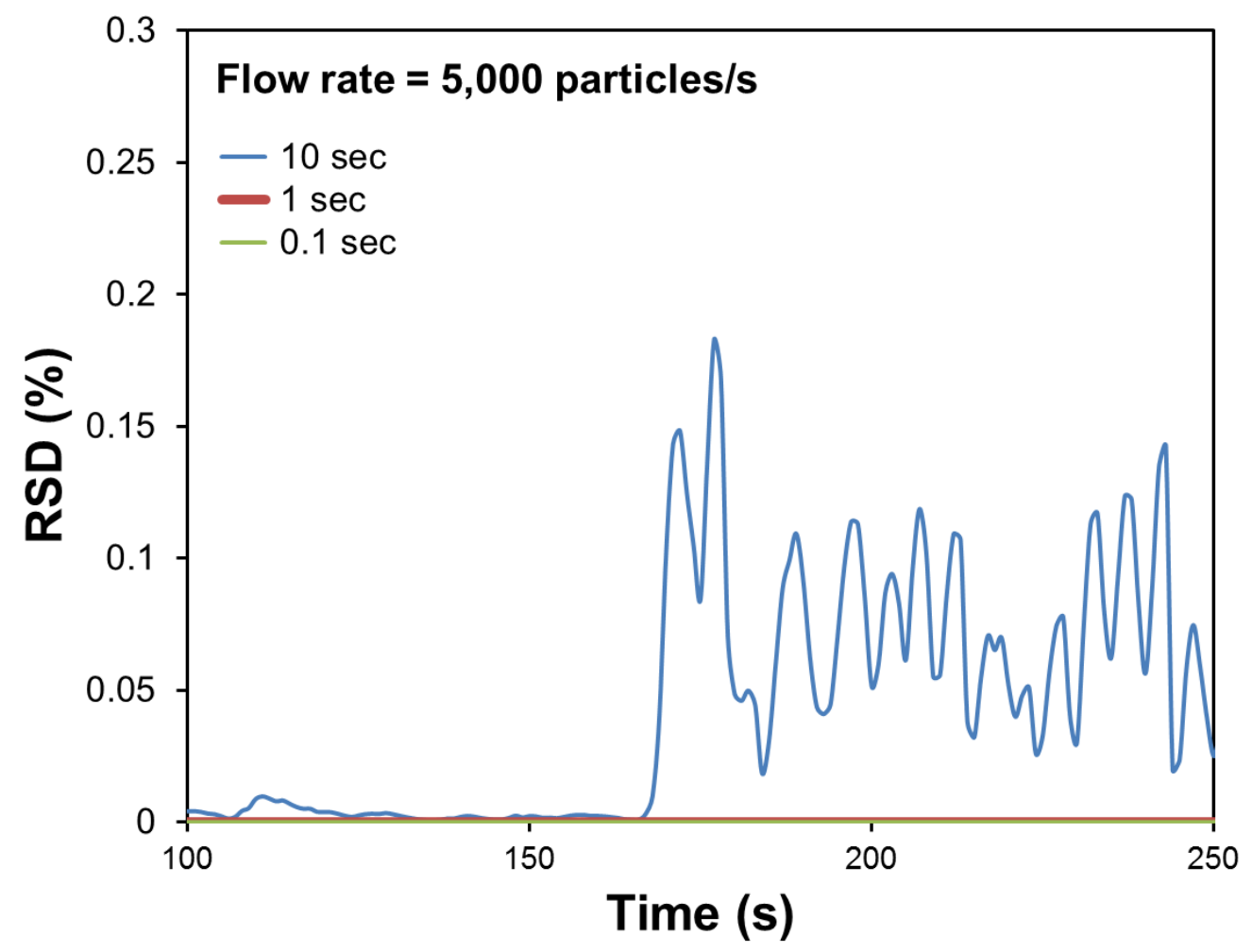

b

Figure 10: RSD (of BU, see equation 2) of API at the mixer's outlet at: (a) 10,000 particles/s and (b) 5,000 particles /s 